\title{
CRÓNICA DE JURISPRUDENCIA DEL TRIBUNAL DE JUSTICIA DE LA UNIÓN EUROPEA, MAYO-AGOSTO 2020
} FERNANDO CASTILLO DE LA TORRE fernando.castillo-de-la-torre@ec.europa.eu

PETRA NEMECKOVA ${ }^{1}$

petra.nemeckova@ec.europa.eu

I. INSTITUCIONES Y PRINCIPIOS FUNDAMENTALES. II. CONTENCIOSO. III. MERCADO INTERIOR, LIBRE CIRCULACIÓN Y CIUDADANÍA EUROPEA. IV. COMPETENCIA. V. APROXIMACIÓN DE LEGISLACIONES. VI. MEDIO AMBIENTE. VII. JUSTICIA, LIBERTAD Y SEGURIDAD.

1 Miembros del Servicio Jurídico de la Unión Europea. 


\section{INSTITUCIONES Y PRINCIPIOS FUNDAMENTALES}

El trámite de audiencia debe ser respetado al adoptar una decisión por la que se suspende la inmunidad de jurisdicción de un funcionario, pero una vulneración del mismo solo genera la anulación de la decisión si, de no haberse producido tal irregularidad, dicho procedimiento podía llevar a un resultado diferente, teniendo en cuenta que, para apreciar la incidencia de la vulneración del derecho del funcionario de que se trate a ser oído, solo son relevantes las consideraciones relacionadas con el interés del servicio (Sentencia de 18 de junio de 2020, C-831/18 P, Comisión/RQ, EU:C:2020:481).

En esta sentencia, el Tribunal de Justicia estimó parcialmente el recurso de casación interpuesto por la Comisión contra una sentencia del Tribunal General (asunto T-29/17, EU:T:2018:717) mediante la cual se había estimado el recurso de anulación interpuesto por RQ, antiguo director general de la Oficina Europea de Lucha contra el Fraude (OLAF), contra una decisión de la Comisión de suspensión de su inmunidad de jurisdicción. El Tribunal de Justicia devolvió el asunto al Tribunal General, ya que el estado del litigio no permitía resolverlo.

Los hechos de este asunto se remontan a 2012, cuando un fabricante de productos de tabaco presentó una denuncia ante la Comisión en la que formulaba graves alegaciones sobre la implicación de un miembro de la Comisión en tentativas de corrupción. La OLAF, de la que RQ era entonces director general, inició una investigación administrativa y, para disponer de pruebas adicionales, solicitó a un testigo que mantuviera una conversación telefónica con una persona supuestamente implicada en la tentativa de corrupción denunciada. Esta conversación telefónica tuvo lugar utilizando, con el acuerdo y en presencia de RQ, un teléfono móvil en los locales de la OLAF. Una vez concluida esa investigación administrativa, se presentó una querella ante un juez belga en la que se invocaba, en particular, la escucha telefónica ilegal. Con el fin de poder tramitar dicha querella, el juez de instrucción belga competente solicitó a la Comisión la suspensión de la inmunidad de RQ para que fuera oído en calidad de investigado. La Comisión estimó dicha solicitud, por lo que RQ interpuso un recurso de anulación de la decisión de suspensión de su inmunidad de jurisdicción. El Tribunal General estimó ese recurso, basándose en que la Comisión había vulnerado el derecho de RQ a ser oído, sin que pudiera excluirse totalmente que la decisión impugnada hubiera podido tener un contenido diferente de no haberse producido tal violación. 
El Tribunal de Justicia, que conoció de un recurso de casación interpuesto por la Comisión, confirmó en primer lugar que la decisión por la que se suspende la inmunidad de un funcionario puede ser objeto de recurso ante los órganos jurisdiccionales de la Unión. El Tribunal de Justicia confirmó a continuación que la Comisión estaba obligada a oír a RQ antes de adoptar la decisión por la que se suspendía su inmunidad de jurisdicción, aun cuando dicha inmunidad de los funcionarios sirva exclusivamente para salvaguardar los intereses de la Unión. En efecto, si bien esta última circunstancia puede dar lugar a que se delimiten los argumentos que el funcionario afectado puede invocar válidamente contra la suspensión de su inmunidad, no puede justificar el hecho de no proceder en absoluto al trámite de audiencia de ese funcionario antes de proceder a la suspensión de su inmunidad.

Por lo que respecta a las limitaciones que pueden imponerse a los derechos consagrados por la Carta, como el derecho a ser oído, el Tribunal de Justicia recordó que el art. 52, apdo. 1, de la Carta exige que cualquier limitación sea establecida por la ley y respete el contenido esencial del derecho fundamental de que se trate. Además, esta disposición exige que, respetando el principio de proporcionalidad, la limitación sea necesaria y responda efectivamente a objetivos de interés general reconocidos por la Unión. Así, aun cuando, en un caso como el de RQ, la falta de audiencia previa a la adopción de la decisión de suspender su inmunidad podría estar justificada por el secreto de instrucción, tal justificación debe reservarse, no obstante, a casos excepcionales. En efecto, no puede presumirse que toda instrucción penal implique sistemáticamente un riesgo de tentativas de ocultación de pruebas e indicios por parte de las personas afectadas, o de concertaciones fraudulentas entre ellas, que justifiquen no informarlas previamente de la existencia de la instrucción que las afecta. De ello se deduce que el Tribunal General consideró fundadamente que, antes de concluir que existía un caso excepcional que justificaba la suspensión de la inmunidad de RQ sin oírlo previamente, la Comisión, respetando el principio de cooperación leal con las autoridades nacionales de que se trataba, debería haber aplicado medidas que permitieran, en la medida de lo posible, respetar su derecho a ser oído, sin poner en peligro los intereses que el secreto de la instrucción pretende preservar.

El Tribunal General tampoco incurrió en error de derecho al declarar que la falta de audiencia de RQ antes de la adopción de la decisión controvertida iba más allá de lo necesario para alcanzar el objetivo de garantizar el secreto de la instrucción y, en consecuencia, no respetaba el contenido esencial de su derecho a ser oído. En un caso como el de RQ, la Comisión está obligada a conseguir que las autoridades nacionales le proporcionen pruebas suficientes para justificar una vulneración grave de su derecho a ser oído. Tal actuación no supone, por su propia naturaleza, una injerencia en el procedimiento del 
Estado miembro de que se trate, que está sujeto a la obligación de cooperación leal establecida en el art. 4 TUE, apdo. 3.

En cuanto a las consecuencias jurídicas de la vulneración del derecho a ser oído de RQ, el Tribunal de Justicia recordó, no obstante, que una vulneración del derecho de defensa solo genera la anulación de la decisión adoptada al término del procedimiento administrativo de que se trate si, de no haberse producido tal irregularidad, dicho procedimiento podía llevar a un resultado diferente. Para apreciar la incidencia de la vulneración del derecho de RQ a ser oído en la legalidad de la decisión por la que se suspende su inmunidad de jurisdicción, solo son relevantes las consideraciones relacionadas con el interés del servicio. Por lo tanto, RQ debería haber demostrado que no cabía excluir totalmente que la decisión de la Comisión habría tenido un contenido diferente si hubiera podido formular alegaciones y presentar pruebas relativas al interés del servicio. Pues bien, como RQ no presentó ninguna alegación ante el Tribunal General relativa a tal demostración, este último incurrió en error de derecho al declarar que la vulneración del derecho a ser oído de RQ justificaba la anulación de la decisión de suspender su inmunidad de jurisdicción.

El Tribunal de Justicia invalida la Decisión 2016/1250 sobre la adecuación de la protección conferida por el Escudo de la Privacidad UE-EE. UU., pero declara que la Decisión 2010/87 de la Comisión, relativa a las cláusulas contractuales tipo para la transferencia de datos personales a los encargados del tratamiento establecidos en terceros países, es válida (Sentencia de 16 de julio de 2020, Facebook Ireland y Schrems, C-311/18, EU:C:2020:559).

El Reglamento (UE) 2016/679 del Parlamento Europeo y del Consejo, relativo a la protección de las personas físicas en lo que respecta al tratamiento de datos personales y a la libre circulación de estos datos (RGPD) dispone que la transferencia de esos datos a un país tercero solo puede, en principio, llevarse a cabo si el país tercero en cuestión garantiza un nivel de protección adecuado a dichos datos. Según el art. 45 del referido reglamento, la Comisión puede constatar que un país tercero, a la vista de su legislación interna o de sus compromisos internacionales, garantiza un nivel de protección adecuado. Si falta esa decisión de adecuación, la mencionada transferencia solo podrá realizarse si el exportador de datos personales, establecido en la Unión, ofrece garantías adecuadas, que pueden, en particular, derivarse de cláusulas tipo de protección de datos adoptadas por la Comisión y si los interesados cuentan con derechos exigibles y acciones legales efectivas [art. 46, apdos. 1 y 2, letra c), del RGPD]. Asimismo, el RGPD establece, de modo preciso, bajo qué 
condiciones puede tener lugar esa transferencia en ausencia de una decisión de adecuación o de garantías adecuadas (art. 49 del RGPD).El Sr. Maximiliam Schrems, nacional austriaco residente en Austria, es usuario de Facebook desde 2008. Como ocurre con el resto de usuarios residentes en la Unión, los datos personales del Sr. Schrems son transferidos, total o parcialmente, por Facebook Ireland a servidores pertenecientes a Facebook Inc., situados en el territorio de Estados Unidos, donde son objeto de tratamiento. El Sr. Schrems presentó una reclamación ante la autoridad irlandesa de control en la que solicitaba, en esencia, que se prohibiesen esas transferencias. Alegó que el derecho y las prácticas de los Estados Unidos no ofrecían suficiente protección frente al acceso, por parte de las autoridades públicas, a los datos transferidos a ese país. Esa reclamación fue desestimada basándose en que, en particular, en su Decisión 2000/520 (denominada Decisión «puerto seguro para la protección de la vida privada»), la Comisión había declarado que los Estados Unidos ofrecían un nivel adecuado de protección. Mediante sentencia de 6 de octubre de 2015, en el asunto C-362/14, el Tribunal de Justicia, en respuesta a una cuestión prejudicial planteada por la High Court (Tribunal Superior, Irlanda), declaró inválida la referida decisión («sentencia Schrems I»).

A raíz de la sentencia Schrems I y de la anulación consecutiva, por parte del órgano jurisdiccional irlandés, de la decisión por la que se desestimaba la reclamación del Sr. Schrems, la autoridad de control irlandesa instó a este a que modificase su reclamación, habida cuenta de la invalidación por el Tribunal de Justicia de la Decisión 2000/520. En su reclamación modificada, el Sr. Schrems sostiene que los Estados Unidos no ofrecen una protección suficiente de los datos que se transfieren a ese país. Solicita la suspensión o prohibición, para el futuro, de las transferencias de sus datos personales desde la Unión a los Estados Unidos que Facebook Ireland lleva a cabo actualmente sobre la base de las cláusulas tipo de protección recogidas en el anexo de la decisión de la Comisión, relativa a las cláusulas contractuales tipo para la transferencia de datos personales a los encargados del tratamiento establecidos en terceros. Al considerar que la tramitación de la reclamación del Sr. Schrems depende, en particular, de la validez de la Decisión 2010/87, la autoridad de control irlandesa inició un procedimiento ante la High Court (Tribunal Superior) para que esta plantease al Tribunal de Justicia una petición de decisión prejudicial. Tras el inicio de ese procedimiento, la Comisión adoptó la Decisión 2016/1250 sobre la adecuación de la protección conferida por el Escudo de la Privacidad UE-EE.UU. (denominada Decisión «Escudo de la Privacidad»).

En su petición de decisión prejudicial, el órgano jurisdiccional remitente preguntaba al Tribunal de Justicia acerca de la aplicabilidad del RGPD a las 
transferencias de datos personales basadas en las cláusulas tipo de protección recogidas en la Decisión 2010/87, acerca del nivel de protección exigido en el antedicho reglamento en el marco de una transferencia de esas características y acerca de las obligaciones que incumben a las autoridades de control en ese contexto. Asimismo, la High Court plantea la cuestión de la validez de la Decisión 2010/87 y de la Decisión 2016/1250.

En su sentencia, el Tribunal de Justicia constata que el examen de la Decisión 2010/87 a la luz de la Carta de los Derechos Fundamentales no ha puesto de manifiesto la existencia de ningún elemento que pueda afectar a su validez. En cambio, declara que la Decisión 2016/1250 es inválida.

Para empezar, el Tribunal de Justicia considera que el derecho de la Unión, y en particular el RGPD, se aplica a una transferencia de datos personales realizada con fines comerciales por un operador económico establecido en un Estado miembro a otro operador económico establecido en un país tercero incluso si, en el transcurso de dicha transferencia o tras ella, esos datos pueden ser tratados con fines de seguridad nacional, defensa y seguridad del Estado por las autoridades del país tercero en cuestión. El Tribunal de Justicia precisa que ese tipo de tratamiento de datos por parte de las autoridades de un país tercero no puede excluir a la referida transferencia del ámbito de aplicación del reglamento.

Por lo que atañe al nivel de protección exigido en el marco de tal transferencia, el Tribunal de Justicia declara que las exigencias establecidas a este efecto por las disposiciones del RGPD, referentes a las garantías adecuadas, los derechos exigibles y las acciones legales efectivas, deben interpretarse en el sentido de que las personas cuyos datos personales se transfieren a un país tercero sobre la base de cláusulas tipo de protección de datos deben gozar de un nivel de protección sustancialmente equivalente al garantizado dentro de la Unión por el antedicho reglamento, interpretado a la luz de la Carta. En este contexto, el Tribunal de Justicia precisa que la evaluación de ese nivel de protección debe tener en cuenta tanto las estipulaciones contractuales acordadas entre el exportador de datos establecido en la Unión y el destinatario de la transferencia establecido en el país tercero de que se trate como, por lo que atañe a un eventual acceso de las autoridades públicas de ese país tercero a los datos personales de ese modo transferidos, los elementos pertinentes del sistema jurídico de dicho país.

Por lo que respecta a las obligaciones que incumben a las autoridades de control en el contexto de una transferencia de esas características, el Tribunal de Justicia declara que, a no ser que exista una decisión de adecuación válidamente adoptada por la Comisión, esas autoridades están, en particular, obligadas a suspender o prohibir una transferencia de datos personales a un país tercero cuando consideran, a la luz de las circunstancias específicas de 
la referida transferencia, que las cláusulas tipo de protección de datos no se respetan o no pueden respetarse en ese país y que las protección de los datos transferidos, exigida por el derecho de la Unión, no puede garantizarse mediante otros medios, si el exportador establecido en la Unión no ha suspendido tal transferencia o puesto fin a esta por sí mismo.

Mientras la decisión de adecuación no haya sido declarada inválida por el Tribunal de Justicia, los Estados miembros y sus órganos, entre ellos las autoridades de control independientes, no pueden ciertamente adoptar medidas contrarias a esa decisión, como serían actos por los que se apreciará con efecto obligatorio que el tercer país al que se refiere dicha decisión no garantiza un nivel de protección adecuado ni, por consiguiente, suspender o prohibir transferencias de datos personales a ese tercer país. No obstante, una decisión de adecuación de la Comisión adoptada en virtud del art. 45, apdo. 3, del RGPD no puede impedir que las personas cuyos datos personales hayan sido o pudieran ser transferidos a un tercer país presenten a la autoridad nacional de control competente una reclamación para la protección de sus derechos y libertades frente al tratamiento de esos datos. De igual forma, una decisión de esa naturaleza no puede dejar sin efecto ni limitar las facultades expresamente reconocidas a las autoridades nacionales de control por el art. 8, apdo. 3 , de la Carta y por los arts. 51, apdo. 1, y 57, apdo. 1, letra a), del antedicho reglamento. Por tanto, incluso habiendo adoptado la Comisión una decisión de adecuación, la autoridad nacional de control competente, a la que una persona haya presentado una reclamación para proteger sus derechos y libertades frente al tratamiento de datos personales que la conciernen, debe poder apreciar con toda independencia si la transferencia de esos datos cumple las exigencias establecidas por el RGPD y, en su caso, interponer un recurso ante los tribunales nacionales, para que estos, si concuerdan en las dudas de esa autoridad sobre la validez de la decisión de adecuación, planteen al Tribunal de Justicia una cuestión prejudicial sobre esta validez.

A continuación, el Tribunal de Justicia examina la validez de la Decisión 2010/87. Según el Tribunal de Justicia, la validez de dicha decisión no queda puesta en entredicho por el mero hecho de que las cláusulas tipo de protección de datos recogidas en ella no vinculen, debido a su carácter contractual, a las autoridades del país tercero al que podrían transferirse los datos. En cambio, el Tribunal de Justicia precisa que esa validez depende de si la referida decisión incluye mecanismos efectivos que permitan en la práctica garantizar que el nivel de protección exigido por el derecho de la Unión sea respetado y que las transferencias de datos personales basadas en esas cláusulas sean suspendidas o prohibidas en caso de violación de dichas cláusulas o de que resulte imposible su cumplimiento. El Tribunal de Justicia constata que la Decisión 2010/87 establece esos mecanismos. 
El responsable del tratamiento establecido en la Unión y el destinatario de la transferencia de datos personales están obligados a comprobar, previamente, el respeto, en el país tercero de que se trate, del nivel de protección exigido por el derecho de la Unión. El destinatario de esa transferencia tiene, en su caso, la obligación de informar al responsable del tratamiento de su eventual incapacidad para cumplir con esas cláusulas, incumbiendo entonces a este último suspender la transferencia de datos o rescindir el contrato. Si el destinatario de la transferencia de datos personales a un país tercero pone en conocimiento del responsable del tratamiento, que la legislación del país tercero de que se trate no le permite cumplir con las cláusulas tipo de protección de datos recogidas en dicho anexo, los datos que ya hayan sido transferidos a ese país tercero y sus copias deben ser devueltos o destruidos en su totalidad. En cualquier caso, la cláusula 6 del anexo de la decisión castiga el incumplimiento de esas cláusulas tipo confiriendo al interesado el derecho a percibir una indemnización por el daño sufrido.

Finalmente, el Tribunal de Justicia procede al examen de la validez de la Decisión 2016/1250 habida cuenta de las exigencias derivadas del RGPD, interpretado a la luz de las disposiciones de la Carta que garantizan el respeto de la vida privada y familiar, la protección de datos de carácter personal y el derecho a la tutela judicial efectiva. A este respecto, el Tribunal de Justicia señala que la referida decisión reconoce, al igual que sucede con la Decisión 2000/520, la primacía de las exigencias relativas a la seguridad nacional, el interés público y el cumplimiento de la ley estadounidense, haciendo así posibles injerencias en los derechos fundamentales de las personas cuyos datos personales se transfieren a ese país tercero. Según el Tribunal de Justicia, las limitaciones de la protección de datos personales que se derivan de la normativa interna de los Estados Unidos relativa al acceso y la utilización, por las autoridades estadounidenses, de los datos transferidos desde la Unión a ese país tercero, y que la Comisión evaluó en la Decisión 2016/1250, no están reguladas conforme a exigencias sustancialmente equivalentes a las requeridas, en el derecho de la Unión, por el principio de proporcionalidad, en la medida en que los programas de vigilancia basados en la mencionada normativa no se limitan a lo estrictamente necesario. Fundándose en las constataciones contenidas en la antedicha decisión, el Tribunal de Justicia señala que, con respecto a algunos programas de vigilancia, de la referida normativa en modo alguno se desprende que existan limitaciones a la habilitación que otorga para la ejecución de esos programas ni tampoco que existan garantías para las personas no nacionales de los Estados Unidos que sean potencialmente objeto de esos programas. El Tribunal de Justicia añade que, si bien la misma normativa establece exigencias que las autoridades estadounidenses deben respetar al aplicar los programas de vigilancia de que se trata, esta no confiere 
a los interesados derechos exigibles a las autoridades estadounidenses ante los tribunales.

Por lo que atañe a la exigencia de tutela judicial, el Tribunal de Justicia declara que, contrariamente a lo que la Comisión consideró en la Decisión 2016/1250, el mecanismo del Defensor del Pueblo contemplado en dicha decisión no proporciona a esas personas ninguna vía de recurso ante un órgano que ofrezca garantías sustancialmente equivalentes a las exigidas en el derecho de la Unión, que puedan asegurar tanto la independencia del Defensor del Pueblo previsto en el antedicho mecanismo como la existencia de normas que faculten al referido Defensor del Pueblo para adoptar decisiones vinculantes con respecto a los servicios de inteligencia estadounidenses. Por todas esas razones, el Tribunal de Justicia declara inválida la Decisión 2016/1250.

\section{El Parlamento europeo puede ejercer parte de sus facultades presupues- tarias en Bruselas, en lugar de en Estrasburgo, de ser necesario para el correcto desarrollo del procedimiento presupuestario (Sentencia de 25 de junio 2020, Francia/Parlamento, C-92/18, EU:C:2020:506).}

Mediante un recurso de anulación, Francia solicitó al Tribunal de Justicia que anulara los actos adoptados por el Parlamento en Bruselas en relación con la aprobación del presupuesto anual de la Unión correspondiente al ejercicio 2018, alegando que los actos impugnados vulneraban el Protocolo sobre las sedes de las instituciones, en virtud del cual el Parlamento está obligado a ejercitar la facultad presupuestaria que le confiere el art. 314 TFUE, apdos. 5, 6 y 9, en principio, íntegramente durante los períodos de sesiones plenarias ordinarias que se celebran en Estrasburgo.

El Parlamento adoptó el calendario de sus períodos de sesiones plenarias de 2017 ya en octubre de 2015. En él se preveía, en particular, la celebración de períodos de sesiones plenarias ordinarias en Estrasburgo (Francia) del 23 al 26 de octubre, del 13 al 16 de noviembre y del 11 al 14 de diciembre de 2017, así como de un período de sesiones plenarias adicionales los días 29 y 30 de noviembre de 2017 en Bruselas (Bélgica). Además, en abril de 2017, el Consejo, el Parlamento y la Comisión elaboraron el calendario pragmático en el que se fijaban las principales fechas previstas por estas instituciones para las diferentes fases del procedimiento presupuestario del ejercicio de 2018 y, en particular, para un posible procedimiento de conciliación.

El 29 de junio de 2017, la Comisión publicó un proyecto de presupuesto anual de la Unión para el ejercicio 2018. El 13 de septiembre de 2017, el Consejo trasladó al Parlamento su posición sobre este proyecto. Tras la votación en la Comisión de Presupuestos y los debates mantenidos durante el 
período de sesiones plenarias ordinarias que se celebró en Estrasburgo del 23 al 26 de octubre de 2017, el Parlamento adoptó, el 25 de octubre de 2017, una resolución legislativa que recogía enmiendas a dicho proyecto. El 31 de octubre de 2017, se inició el procedimiento de conciliación presupuestaria entre el Parlamento y el Consejo. Este procedimiento condujo a la adopción, el 18 de noviembre de 2017, de un acuerdo sobre un texto conjunto de presupuesto anual de la Unión para el ejercicio 2018.

El 30 de noviembre de 2017, el Consejo aprobó el texto conjunto de presupuesto anual de la Unión para el ejercicio 2018. El Parlamento incluyó el debate y la votación de este proyecto en el orden del día del período de sesiones plenarias adicionales de 29 y 30 de noviembre de 2017 en Bruselas. Mediante resolución legislativa de 30 de noviembre de 2017, el Parlamento aprobó dicho proyecto. El mismo día, el presidente del Parlamento declaró en sesión plenaria que el presupuesto anual de la Unión correspondiente al ejercicio 2018 había quedado definitivamente adoptado.

En una sentencia anterior [de 2 de octubre de 2018, Francia/Parlamento (Ejercicio de las facultadas presupuestarias), C-73/17, EU:C:2018:787], el Tribunal de Justicia ya desestimó el recurso interpuesto por Francia contra los actos adoptados por el Parlamento en el marco del procedimiento que condujo a la adopción del presupuesto de la Unión para el ejercicio 2017. No obstante, a pesar de esta sentencia anterior, Francia confirmó que pretendía mantener su recurso relativo al presupuesto de la Unión para el ejercicio 2018.

Retomando sus conclusiones de esta sentencia anterior, el Tribunal de Justicia recordó, en primer lugar, que en la medida en que el Protocolo sobre las sedes de las instituciones y el art. 314 TFUE tienen el mismo valor jurídico, las exigencias dimanantes del primero de ellos no pueden, como tales, prevalecer sobre las que se derivan del segundo, y viceversa. Ambas deben aplicarse caso por caso, conciliándose debidamente y respetando un justo equilibrio entre ellas. Además, conforme a reiterada jurisprudencia, el Protocolo sobre las sedes de las instituciones se rige por el respeto mutuo de las respectivas competencias de los Estados miembros y el Parlamento y por un deber recíproco de cooperación leal.

Por consiguiente, aunque el Parlamento está obligado a ejercitar sus facultades presupuestarias durante un período de sesiones plenarias ordinarias en Estrasburgo, esta exigencia resultante del citado protocolo no impide que, de ser necesario para el correcto desarrollo del procedimiento presupuestario con arreglo al art. 314 TFUE, el presupuesto anual sea objeto de debate y votación durante un período de sesiones plenarias adicionales en Bruselas. Un desarrollo del procedimiento que primara de manera absoluta la observancia del protocolo en detrimento de la plena participación del Parlamento en el 
citado procedimiento sería incompatible con la necesaria conciliación de las obligaciones derivadas de estas disposiciones.

Por lo que respecta el control judicial del cumplimiento de las exigencias dimanantes del protocolo y del TFUE, al efectuar la necesaria conciliación entre las obligaciones previstas en sendos actos, el Tribunal de Justicia recordó igualmente que el Parlamento dispone de un margen de apreciación que se deriva de las exigencias asociadas al correcto desarrollo del procedimiento presupuestario. Por tanto, este control judicial tiene por objeto determinar si el Parlamento, al ejercer una parte de sus facultades presupuestarias durante un período de sesiones plenarias adicionales, ha incurrido en errores de apreciación a este respecto.

Francia alegó que, aunque, en el marco fijado por el calendario de períodos de sesiones plenarias ordinarias para el año 2017, el período de sesiones plenarias adicionales celebrado en Bruselas los días 29 y 30 de noviembre de 2017 constituía la única posibilidad de que el Parlamento se pronunciara sobre el texto conjunto de presupuesto anual para el ejercicio 2018 en el plazo previsto en el art. 314 TFUE, apdo. 6, la configuración de este calendario parlamentario adolecía de un error de apreciación. El Tribunal de Justicia rechazó tal premisa al declarar, al igual que en la sentencia en el asunto C-73/17, que, en el momento de la fijación del calendario de las sesiones plenarias ordinarias en octubre de 2015, tanto el recurso al procedimiento de conciliación como la fecha en que dicho procedimiento comenzaría y, en su caso, finalizaría debido a la adopción de un acuerdo sobre un texto conjunto de presupuesto anual son, por principio, inciertos. Del mismo modo, tras el establecimiento, en abril de 2017, del calendario pragmático relativo al procedimiento presupuestario para el ejercicio 2018, todavía se desconocía si el Comité de Conciliación podría alcanzar un acuerdo de conciliación y, en su caso, en qué fecha.

\section{CONTENCIOSO}

El Tribunal de Justicia precisa las condiciones para que se reconozca que una instancia que conoce de un litigio sea considerado órgano jurisdiccional en el sentido del artículo 267 TFEU (Sentencias de 9 de julio de 2020, VQ/Land Hessen, C-272/19, EU:C:2020:535, y de 16 de julio de 2020, UX, C-658/18, EU:C:2020:572).

En el ámbito de las reglas del contencioso de los Tribunales de la Unión, y en particular de la noción de órgano jurisdiccional, destacan los asuntos C-272/19 y C-658/18. En la sentencia relativa al primero, el Tribunal de 
Justicia examina desde el punto de vista de la admisibilidad de la petición de decisión prejudicial las dudas expresadas por el Verwaltungsgericht (tribunal administrativo) de Wiesbaden (Alemania) respecto a su propia independencia frente al poder legislativo o al poder ejecutivo.

Esas dudas se basaban en el hecho de que, según el tribunal alemán, en primer lugar, los jueces son nombrados y ascendidos por el ministro de Justicia; en segundo lugar, la calificación de los jueces se regula por el Ministerio de Justicia con arreglo a las mismas disposiciones aplicables a los funcionarios; en tercer lugar, los datos personales y los datos de contacto profesionales de los jueces son gestionados por dicho ministerio, que, de este modo, tiene acceso a esos datos; en cuarto lugar, para atender una necesidad temporal de personal, los funcionarios pueden ser nombrados jueces temporales, $y$, en quinto lugar, dicho ministerio ordena la organización externa e interna de los órganos jurisdiccionales, establece la asignación de personal, los medios de comunicación y el equipo informático de los órganos jurisdiccionales y decide también los desplazamientos profesionales al extranjero de los jueces.

Aplicando su jurisprudencia relativa al concepto de "órgano jurisdiccional» en el sentido del derecho de la Unión y en particular a la independencia exigida para poder ser considerado como tal, el Tribunal de Justicia declara que los aspectos invocados por el Verwaltungsgericht Wiesbaden para apoyar sus dudas no bastan, en sí mismos, para concluir que dicho tribunal no sea independiente. El Tribunal de Justicia, apoyándose en la reciente sentencia Banco de Santander (C-274/14, EU:C:2020:17), recuerda que las garantías de independencia e imparcialidad de las que deben disfrutar los órganos jurisdiccionales de los Estados miembros postulan la existencia de reglas, especialmente en lo referente a la composición del órgano, así como al nombramiento, a la duración del mandato y a las causas de inhibición, recusación y cese de sus miembros, que permitan excluir toda duda legítima en el ánimo de los justiciables en lo que respecta a la impermeabilidad de dicho órgano frente a elementos externos y en lo que respecta a su neutralidad con respecto a los intereses en el litigio. Ahora bien, el mero hecho de que los poderes legislativo o ejecutivo intervengan en el proceso de nombramiento de un juez no da lugar a la creación de una dependencia entre aquellos y este, ni hace surgir dudas en cuanto a su imparcialidad, si, una vez nombrado, no está sometido a presión alguna y no recibe instrucciones en el ejercicio de sus funciones.

En el asunto C-658/18, UX, el Tribunal de Justicia examinó la figura italiana del giudice di pace (juez de paz). Los jueces de paz son jueces honorarios, obligados a cumplir los deberes establecidos para los jueces de carrera, nombrados por procedimiento previsto en la ley y que perciben indemnizaciones por determinadas actuaciones en el ámbito de sus funciones (por ejemplo, por cada vista celebrada). 
Una vez establecido que no caben dudas de que el juez de paz cumple los criterios relativos a su origen legal, a su permanencia y a su aplicación de normas jurídicas, el Tribunal de Justicia se centró en el examen del criterio de la independencia y del carácter obligatorio de la jurisdicción de que se trate.

Por lo que respecta el concepto de «independencia», el Tribunal de Justicia recordó que este concepto comporta dos aspectos. El primero de ellos, de índole externa, se traduce en el principio de inamovilidad que exige, en particular, que los jueces puedan permanecer en el ejercicio de sus funciones en tanto no hayan alcanzado la edad de jubilación forzosa o hasta que termine su mandato cuando este tenga una duración determinada. El segundo aspecto del concepto de «independencia», de índole interna, se asocia al concepto de imparcialidad y se refiere a la equidistancia que debe guardar el órgano de que se trate con respecto a las partes en el litigio y a sus intereses respectivos en relación con el objeto del litigio. Este aspecto exige el respeto de la objetividad y la inexistencia de cualquier interés en la solución del litigio que no sea el de la estricta aplicación de la norma jurídica.

En cuanto a la inamovilidad de los jueces de paz, el Tribunal de Justicia observó que los jueces de paz son nombrados mediante decreto del presidente de la República Italiana, a propuesta del consejo judicial territorialmente competente, que estos jueces tienen un mandato de cuatro años de duración, renovable a su término por el mismo período y que permanecen en funciones, en principio, hasta la expiración de su mandato de cuatro años, siempre que este último no sea renovado. Además, los supuestos de su separación y los procedimientos específicos correspondientes están determinados a escala nacional en disposiciones legales expresas. Los jueces de paz ejercen sus funciones con total autonomía, sin perjuicio de las normas en materia disciplinaria, y sin presiones externas que puedan influir en sus decisiones.

Por lo que se refiere al requisito de imparcialidad, el Tribunal de Justicia se limitó a señalar que el Tribunal de Justicia ya ha respondido, en repetidas ocasiones, a peticiones de decisión prejudicial acerca del estatuto de los jueces, sin albergar dudas sobre la independencia de los órganos jurisdiccionales remitentes que las plantearon.

En segundo término, centrándose en el tema del carácter obligatorio de la jurisdicción del órgano jurisdiccional remitente, el Tribunal de Justicia observó que la demanda se formuló correctamente dentro de los límites de la competencia del juez que conoce del asunto en función del valor y de la competencia territorial de este. En lo que atañe al carácter contradictorio del procedimiento pendiente ante el juez, el Tribunal de Justicia recordó que el art. 267 TFUE no supedita la remisión del asunto al Tribunal de Justicia al carácter contradictorio del procedimiento ante el órgano jurisdiccional remitente. En cambio, los órganos jurisdiccionales nacionales solo pueden 
pedir al Tribunal de Justicia que se pronuncie si ante ellos está pendiente un litigio y si deben adoptar su resolución en el marco de un procedimiento que concluya con una decisión de carácter jurisdiccional.

La Comisión puede solicitar al Tribunal de Justicia la imposición del pago de una suma a tanto alzado con arreglo al artículo 260 TFUE, apartado 3, aun cuando el incumplimiento finalizó cuando el Tribunal de Justicia examinó los hechos, en la medida en que la condena al pago de una suma a tanto alzado se apoya en la apreciación de las consecuencias de la falta de ejecución de las obligaciones del Estado miembro de que se trate sobre los intereses privados y públicos, en particular cuando el incumplimiento ha persistido durante largo tiempo (sentencias de 16 de julio de 2020, Comisión/Rumanía, C-549/18, EU:C:2020:563, y Comisión/Irlanda, C-550/18, EU:C:2020:564).

Mediante estas dos sentencias, el Tribunal de Justicia condenó a Rumanía e Irlanda a pagar a la Comisión respectivas sumas al tanto alzado, por no haber traspuesto de forma completa, en el plazo establecido, la Directiva (UE) 2015/849 del Parlamento Europeo y del Consejo, relativa a la prevención de la utilización del sistema financiero para el blanqueo de capitales o la financiación del terrorismo. La Comisión interpuso ante el Tribunal de Justicia sendos recursos por incumplimiento, al considerar que estos Estados miembros no habían transpuesto de forma completa la directiva en cuestión en el plazo que les había sido señalado en los respectivos dictámenes motivados, ni habían comunicado las medidas de transposición correspondientes. La Comisión además solicitó, sobre la base del art. 260 TFUE, apdo. 3, que se condenara a Rumanía y a Irlanda, por un lado, al pago de una multa coercitiva diaria, a partir del pronunciamiento de la sentencia, por haber incumplido la obligación de comunicar las medidas de transposición de esta misma directiva y, por otro lado, al pago de una suma a tanto alzado. Posteriormente la Comisión desistió de su solicitud de imposición de la multa coercitiva diaria, al haber quedado esta pretensión sin objeto a raíz de la transposición completa de la directiva al derecho rumano y al derecho irlandés, respectivamente.

Los dos Estados miembros demandados se oponían a la aplicación del régimen de sanciones establecido en el art. 260 TFUE, apdo. 3. Sostenían que la pretensión de la Comisión de imponer el pago de una suma a tanto alzado no solo no estaba justificada, sino que tampoco era proporcionada a la vista de los hechos del caso y del objetivo de este tipo de sanción pecuniaria. Reprochaban a la Comisión no haber motivado, de manera detallada y caso por caso, su decisión de solicitar la imposición de tal sanción. 
El Tribunal de Justicia estimó los recursos interpuestos por la Comisión. Declaró que el art. 260 TFUE, apdo. 3, se aplica en los presentes asuntos. Recordó al respecto que la obligación de comunicar las medidas de transposición, en el sentido de esta disposición, se refiere a la obligación de los Estados miembros de transmitir información suficientemente clara y precisa sobre las medidas de transposición de una directiva. La conformidad con esta obligación implicaba, en los presentes asuntos, que los Estados miembros indicaran, para cada disposición de la citada directiva, la disposición o disposiciones nacionales que garantizaban su transposición. Señalando que la Comisión había acreditado la falta de comunicación, por parte de Rumanía y de Irlanda, de las medidas de transposición de la directiva en el plazo señalado por el dictamen motivado, el Tribunal de Justicia declaró, en primer término, que el incumplimiento así constatado está comprendido en el ámbito de aplicación de dicha disposición.

En segundo término, el Tribunal de Justicia recordó que no incumbe a la Comisión motivar caso por caso su decisión de solicitar una sanción pecuniaria en virtud el art. 260 TFUE, apdo. 3. En efecto, consideró que las condiciones de aplicación de esta disposición no pueden ser más restrictivas que las que prevén la aplicación del art. 258 TFUE, en la medida en que el art. 260 TFUE, apdo. 3, no constituye sino una modalidad accesoria del procedimiento por incumplimiento, cuya aplicación está comprendida en la facultad discrecional de la Comisión, sobre la que el Tribunal de Justicia no puede ejercer control jurisdiccional. Esta ausencia de motivación no afecta a las garantías procesales del Estado miembro de que se trate, en la medida en que el Tribunal de Justicia, cuando impone tal sanción, está sujeto a una obligación de motivación.

Sin embargo, el Tribunal de Justicia precisó que la Comisión sigue estando obligada a motivar la naturaleza y el importe de la sanción pecuniaria solicitada, teniendo en cuenta a este respecto las directrices que adoptó ya que, en el marco de un procedimiento iniciado en aplicación del art. 260 TFUE, apdo. 3, el Tribunal de Justicia solo dispone de una facultad de apreciación delimitada. En efecto, en caso de que este último declare la existencia de un incumplimiento, las propuestas de la Comisión vinculan al Tribunal de Justicia en cuanto a la naturaleza de la sanción pecuniaria que puede imponer y en cuanto al importe máximo de la sanción que puede pronunciar.

En tercer lugar, por lo que respecta la imposición del pago de una suma a tanto alzado en los presentes asuntos, el Tribunal de Justicia recordó que el objetivo perseguido por la introducción del mecanismo que figura en el art. 260 TFUE, apdo. 3, no solo es incitar a los Estados miembros a poner fin lo antes posible a un incumplimiento que, de no existir dicha medida, tendría tendencia a persistir, sino también agilizar y acelerar el procedimiento 
para la imposición de sanciones económicas en los casos de incumplimiento de la obligación de informar de las medidas nacionales de transposición de una directiva adoptada de conformidad con el procedimiento legislativo. De este modo, el Tribunal de Justicia declaró que un recurso de la Comisión que, como en el caso de autos, solicitaba la imposición del pago de una suma a tanto alzado no puede desestimarse por resultar desproporcionado por el mero hecho de tener por objeto un incumplimiento que, aun habiéndose prolongado en el tiempo, finalizó cuando el Tribunal de Justicia examinó los hechos, en la medida en que la condena al pago de una suma a tanto alzado se apoya en la apreciación de las consecuencias de la falta de ejecución de las obligaciones del Estado miembro de que se trate sobre los intereses privados y públicos, en particular cuando el incumplimiento ha persistido durante largo tiempo.

Una institución de la Unión no puede establecer condiciones y procedimientos específicos que sustraigan litigios que implican la interpretación o la aplicación del derecho de la Unión a la competencia de los órganos jurisdiccionales de los Estados miembros y del juez de la Unión (Sentencia de 25 de junio de 2020, CSUE/KF, C-14/19 P, EU:C:2020:492).

En esta sentencia el Tribunal de Justicia confirmó, en casación, la sentencia del Tribunal General (T-286/15, EU:T:2018:718) que, por una parte, había anulado dos decisiones del director del Centro de Satélites de la Unión Europea (CSUE) por las que, por causa disciplinaria, se suspendía y separaba del servicio a KF, agente contractual, y la decisión de la Comisión de Recursos del CSUE dictada en el mismo procedimiento, y, por otra parte, había condenado al CSUE a abonar a KF la cantidad de 10000 euros en concepto de indemnización del daño moral sufrido. El Estatuto del personal del CSUE no preveía ningún control de legalidad contra las decisiones de la Comisión de Recursos del CSUE.

KF interpuso un recurso ante el Tribunal General por el que solicitaba que se anularan las decisiones controvertidas y se condenara al CSUE a abonarle los salarios no percibidos y la cantidad de 500000 euros por el perjuicio moral sufrido. Además, propuso, sobre la base del art. 277 TFUE, una excepción de ilegalidad del art. 28, apdo. 6, del Estatuto del personal del CSUE, alegando que esta disposición convierte a la Comisión de Recursos en la única instancia de control de legalidad de las decisiones del director del CSUE, sustrayendo así estas decisiones a todo control judicial. El Tribunal General estimó la excepción de ilegalidad y estimó parcialmente el recurso, 
por lo que el CSUE interpuso un recurso de casación contra la sentencia recurrida.

$\mathrm{Al}$ examinar, en primer lugar, los motivos basados en la falta de competencia del Tribunal General para conocer del recurso en primera instancia y en la inadmisibilidad de este, el Tribunal de Justicia declaró, en primer término, que el art. 263 TFUE, párr. quinto, no autoriza a una institución de la Unión a establecer condiciones y procedimientos específicos que sustraigan litigios que implican la interpretación o la aplicación del derecho de la Unión a la competencia de los órganos jurisdiccionales de los Estados miembros y del juez de la Unión. A su juicio, este es el efecto de la disposición que atribuye a la Comisión de Recursos competencias exclusivas para aplicar e interpretar, sin posibilidad de recurso, el Estatuto del personal del CSUE, que se recoge en una decisión adoptada por el Consejo e incluye por ello disposiciones del derecho de la Unión. Por lo tanto, la atribución exclusiva de estas competencias a dicha Comisión es contraria a la jurisprudencia del Tribunal de Justicia según la cual el art. 19 TUE confía a los órganos jurisdiccionales nacionales y al Tribunal de Justicia la tarea de garantizar la plena aplicación del derecho de la Unión.

En segundo término, el Tribunal de Justicia declaró que las decisiones controvertidas cumplían los requisitos exigidos para ser consideradas actos impugnables en el sentido del art. 263 TFUE. En efecto, fijan definitivamente la posición del CSUE y están destinadas a producir efectos jurídicos obligatorios que pueden afectar a los intereses de KF, que es su destinataria y a quien le resultan lesivas, modificando sustancialmente su situación jurídica. Por otra parte, el Tribunal de Justicia señaló que la relación laboral existente entre KF y el CSUE, a la que no es aplicable el art. 270 TFUE, no permite considerar que el litigio no enfrenta al CSUE con un tercero en el sentido del art. 263 TFUE, párr. primero. Por lo tanto, esta relación laboral no excluye este litigio del ámbito de aplicación de dicha disposición.

En tercer término, el Tribunal de Justicia recordó que la preservación de la coherencia del sistema jurisdiccional exige, en principio, que el juez de la Unión renuncie al ejercicio de las competencias que le confiere el art. 263 TFUE cuando la situación jurídica del demandante se inscribe en el marco de relaciones contractuales comprendidas en el ámbito de las competencias previstas en los arts. 272 TFUE o 274 TFUE. Sin embargo, en un contexto en el que, con arreglo a los arts. 272 TFUE o 274 TFUE, se excluye todo control jurisdiccional por los órganos jurisdiccionales nacionales y por el juez de la Unión de las decisiones adoptadas por el CSUE, esta renuncia del juez de la Unión no está justificada por el objetivo de preservar la coherencia del sistema jurisdiccional. En tales circunstancias, para garantizar la existencia 
de un control judicial efectivo, corresponde al juez de la Unión ejercer las competencias que le confiere el art. 263 TFUE.

Un Estado miembro no puede interponer un recurso de anulación contra un escrito de la Comisión por la que se informa a las autoridades nacionales de que las condiciones de exención de la obligación de poner a disposición los recursos propios de la Unión no se cumplen y se insta a las autoridades a adoptar las medidas necesarias para consignar en el haber de la cuenta de la Comisión el importe de que se trata; no obstante, cuando un Estado miembro ha puesto a disposición de la Comisión un importe de recursos propios de la Unión expresando sus reservas en cuanto al fundamento de la postura de esta institución y el procedimiento de diálogo no ha permitido poner fin a la controversia entre dicha institución y el Estado miembro, este puede reclamar una indemnización por enriquecimiento sin causa de la Unión y, en su caso, interponer un recurso ante el Tribunal General a tal efecto (Sentencia de 9 de julio de 2020, República Checa/Comisión, C-575/18 P, EU:C:2020:530).

Mediante esta sentencia, el Tribunal de Justicia, en formación de Gran Sala, se pronunció sobre las condiciones de acceso de los Estados miembros a la tutela judicial efectiva en caso de litigios relativos al alcance de la responsabilidad financiera de estos respecto a la Unión en materia de recursos propios de ésta.

El 30 de mayo de 2008, la Oficina Europea de Lucha contra el Fraude (OLAF) aprobó un informe relativo a una investigación destinada a comprobar importaciones de encendedores de bolsillo de piedra procedentes de Laos e instó a las autoridades nacionales a realizar auditorías a los importadores en cuestión e incoar un procedimiento administrativo de recaudación. Las autoridades checas adoptaron medidas para proceder a la liquidación complementaria y a la recaudación fiscal, pero señalaron que, en algunos de dichos casos, no había sido posible recaudar el importe de los recursos propios de la Unión. Mediante escrito de 20 de enero de 2015, la Comisión Europea informó a esas autoridades de que no podía eximirse a la República Checa de su obligación de poner a disposición los recursos propios de la Unión y las instó a proceder al pago del importe de que se trataba, puntualizando que todo retraso daría lugar al pago de intereses.

En desacuerdo con la postura adoptada por la Comisión en ese escrito, la República Checa interpuso ante el Tribunal General un recurso de anulación contra la decisión de esa institución supuestamente contenida en dicho escrito. Mediante auto, el Tribunal General estimó la excepción de admisibilidad 
propuesta por la Comisión y, en consecuencia, declaró la inadmisibilidad del recurso, ya que consideró que éste se dirigía contra un acto que no podía ser objeto de un recurso de anulación en la medida en que dicho acto no producía efectos jurídicos obligatorios. La República Checa interpuso un recurso de casación ante el Tribunal de Justicia aduciendo, en esencia, que la inadmisibilidad de su recurso la privaba de una tutela judicial efectiva, puesto que no disponía de ninguna vía de recurso para obtener un control jurisdiccional efectivo de la postura adoptada por la Comisión.

El Tribunal de Justicia comenzó indicando que, en el estado actual del derecho de la Unión, las obligaciones de recaudación, constatación y consignación en cuenta de los recursos propios de la Unión vienen impuestas directamente a los Estados miembros. Así pues, la Comisión no dispone de facultad de decisión alguna que le permita obligar a los Estados miembros a constatar y a poner a su disposición importes de esos recursos. El Tribunal de Justicia concluyó de lo anterior que admitir un recurso de anulación contra un escrito como el controvertido, con el fin de controlar si es fundada la obligación de un Estado miembro de poner a disposición de la Comisión tales importes, equivaldría a inobservar el sistema de recursos propios de la Unión, tal como está establecido en el derecho de la Unión. Pues bien, no corresponde al Tribunal de Justicia modificar la elección hecha, a este respecto, por el legislador de la Unión.

A continuación, el Tribunal de Justicia declaró que la facultad de la Comisión de someter a la apreciación del Tribunal de Justicia, en el marco de un recurso por incumplimiento, una controversia que la enfrenta a un Estado miembro acerca de la obligación de este de poner a disposición de esta institución un determinado importe de recursos propios de la Unión es inherente al sistema de recursos propios, tal como este está diseñado actualmente en el derecho de la Unión. Añadió que, cuando un Estado miembro procede a la puesta a disposición de un importe de dichos recursos sujetándola a reservas en cuanto a su obligación de hacerlo, corresponde a la Comisión, de conformidad con el principio de cooperación leal, entablar un diálogo constructivo con ese Estado miembro a fin de determinar las obligaciones que incumben a este último. Si fracasa ese diálogo, esta institución está facultada para interponer un recurso por incumplimiento contra dicho Estado miembro. En efecto, el hecho de someter a reservas la puesta a disposición de recursos propios de la Unión justificaría la declaración de incumplimiento en el supuesto de que el Estado miembro de que se trate estuviera efectivamente obligado a proceder a tal puesta a disposición.

Sin embargo, habida cuenta de la facultad discrecional de que goza la Comisión en relación con la interposición de un recurso por incumplimiento, el Tribunal de Justicia llegó a la conclusión de que este recurso no ofrece 
ninguna garantía al Estado miembro de que se trate de que el juez vaya a dirimir la controversia que enfrenta a ese Estado miembro con esa institución acerca de la puesta a disposición de recursos propios de la Unión. Añadió que, no obstante lo anterior, cuando un Estado miembro ha puesto a disposición de la Comisión un importe de recursos propios de la Unión expresando sus reservas en cuanto al fundamento de la postura de esta institución y el procedimiento de diálogo no ha permitido poner fin a la controversia entre dicha institución y el Estado miembro, este puede reclamar una indemnización por enriquecimiento sin causa de la Unión y, en su caso, interponer un recurso ante el Tribunal General a tal efecto.

A este respecto, el Tribunal de Justicia recordó que la acción basada en el enriquecimiento sin causa de la Unión, que puede interponerse en virtud de los arts. 268 TFUE y 340 TFUE, párr. segundo, requiere que se demuestre un enriquecimiento sin base legal válida de la parte demandada y un empobrecimiento de la parte demandante relacionado con dicho enriquecimiento. Para examinar tal acción, correspondería al Tribunal General apreciar, en particular, si el empobrecimiento del Estado miembro demandante, que corresponde a la puesta a disposición de la Comisión de un importe de recursos propios de la Unión que ese Estado miembro ha impugnado, y el correlativo enriquecimiento de esta institución están justificados por las obligaciones impuestas a dicho Estado miembro en virtud del derecho de la Unión en materia de recursos propios de la Unión o bien si, por el contrario, carecen de tal justificación. Por consiguiente, el Tribunal de Justicia, considerando que un Estado miembro no queda privado de toda tutela judicial efectiva en caso de desacuerdo con la Comisión sobre las obligaciones de aquel en materia de recursos propios de la Unión, desestimó el recurso de casación en su totalidad.

El juez de la Unión solo podrá conocer de un recurso basado en el art. 263 TFUE contra un título ejecutivo del cumplimiento de un contrato entre un particular y una de las instituciones de la Unión, si el acto impugnado está destinado a producir efectos jurídicos vinculantes ajenos a la relación contractual entre las partes y que impliquen el ejercicio de prerrogativas de poder público atribuidas a la institución contratante, siempre que el contrato en cuestión contenga una cláusula compromisoria en favor del juez de la Unión (Sentencia de 16 de julio de 2020, ADR Center/Comisión, C-584/17, EU:C:2020:576).

En este asunto, el Tribunal de Justicia desestimó el recurso de casación interpuesto por la sociedad italiana ADR Center contra la sentencia del Tribunal General, mediante la que este último había desestimado su recurso por el que solicitaba, por un lado, la anulación de una decisión de la Comisión, 
relativa a la recuperación de una parte de la contribución financiera pagada a ADR en ejecución de tres acuerdos de subvención y, por otro, la condena de esta institución a pagarle el saldo restante adeudado en virtud de los citados acuerdos así como una indemnización de daños y perjuicios. Esta decisión constituía título ejecutivo en el sentido del art. 299 TFUE.

En este contexto, el Tribunal de Justicia se pronunció, en primer lugar, a favor de la facultad de la Comisión de adoptar una decisión que constituye título ejecutivo en el marco de una relación contractual. A este respecto, tras resaltar que el art. 299 TFUE, párr. primero, es aplicable a todos los actos por los que se establece una obligación pecuniaria de las instituciones de la Unión, el Tribunal de Justicia precisó que esta disposición no constituye por sí sola una base jurídica suficiente para la adopción de actos con fuerza de título ejecutivo. Por otra parte, el Tribunal de Justicia declaró que el art. 79, apdo. 2, del Reglamento financiero atribuye a la Comisión la facultad de formalizar el devengo de títulos de crédito a cargo de personas distintas de los Estados miembros en una decisión que constituye título ejecutivo y que esa misma disposición va destinada a aplicarse a todas las operaciones comprendidas en el presupuesto de la Unión. Por lo tanto, el Tribunal de Justicia declaró que dichas disposiciones atribuían competencia a la Comisión para adoptar una decisión con fuerza de título ejecutivo, a pesar de tratarse de una obligación pecuniaria de naturaleza contractual.

Seguidamente, el Tribunal de Justicia puntualizó que, cuando exista un contrato entre la parte demandante y una de las instituciones de la Unión, el juez de la Unión solo podrá conocer de un recurso basado en el art. 263 TFUE si el acto impugnado está destinado a producir efectos jurídicos vinculantes ajenos a la relación contractual entre las partes y que impliquen el ejercicio de prerrogativas de poder público atribuidas a la institución contratante. Cuando la Comisión hace uso de tales prerrogativas de poder público para adoptar actos cuyos efectos jurídicos se despliegan fuera del marco contractual, tales como una decisión con fuerza de título ejecutivo, esos actos están sometidos a la jurisdicción del juez de la Unión y pueden ser impugnados mediante un recurso de anulación interpuesto sobre la base del art. 263 TFUE. No obstante, la facultad de la Comisión de adoptar decisiones con fuerza de título ejecutivo en el marco de una relación contractual debe limitarse a los contratos que contienen una cláusula compromisoria en favor del juez de la Unión, con el fin de evitar restringir la competencia de los órganos jurisdiccionales nacionales y para no permitir a la Comisión eludir el reparto de competencias entre estos y el juez de la Unión. 


\section{MERCADO INTERIOR, LIBRE CIRCULACIÓN Y CIUDADANÍA EUROPEA}

Un miembro de la familia de un ciudadano de la Unión que no tiene la nacionalidad de un Estado miembro, pero que es titular de una tarjeta de residencia permanente, tiene la condición de miembro de familia y está exento de la obligación de obtener un visado para entrar en el territorio de los Estados miembros (Sentencia de 18 de junio, Ryanair, C-754/18, EU:C:2020:478).

En el ámbito de ciudadanía de la Unión destaca esta sentencia en la que el Tribunal de Justicia examinó la cuestión de si los titulares de una tarjeta de residencia permanente están exentos, con arreglo a la Directiva 2004/38/ CE, relativa al derecho de los ciudadanos de la Unión y de los miembros de sus familias a circular y residir libremente en el territorio de los Estados miembros, de la obligación de visado, y si esta dispensa incluye a los nacionales de terceros Estados cuando la tarjeta de residencia les ha sido expedida por un Estado miembro que, como el Reino Unido, no formaba parte del espacio Schengen cuando tuvieron lugar los hechos del litigio.

Los hechos del litigio principal se remontan a octubre de 2017 cuando la policía del aeropuerto de Budapest (Hungría) llevó a cabo el control de los pasajeros de un vuelo procedente de Londres (Reino Unido) operado por Ryanair. Durante ese control comprobó que un pasajero de nacionalidad ucraniana, que estaba en posesión de un pasaporte no biométrico y de una tarjeta de residencia permanente válida, expedida por el Reino Unido con arreglo a la directiva relativa al derecho de los ciudadanos de la Unión y de los miembros de sus familias a circular y residir libremente en el territorio de los Estados miembros, no disponía de visado. Al considerar que, a falta de visado, este pasajero no disponía de todos los documentos de viaje exigidos para poder entrar en territorio húngaro, la policía no autorizó su entrada en Hungría y pidió a Ryanair que lo devolviera a Londres. Además, consideró que Ryanair no había adoptado las medidas que le incumbían como transportista para cerciorarse de que dicho pasajero contaba con los documentos de viaje exigidos y, por ese motivo, impuso a dicha compañía aérea una multa por importe de 3000 euros.

Ryanair impugnó ante el tribunal competente húngaro la legalidad de la resolución administrativa mediante la que se le impuso la multa. Entre otras cosas, alegó que el pasajero en cuestión estaba autorizado a entrar en territorio húngaro sin visado, puesto que disponía de una tarjeta de residencia permanente válida expedida por el Reino Unido con arreglo a la directiva. Asimismo, el tribunal húngaro deseaba saber si esta tarjeta de residencia es 
prueba suficiente de que su titular tiene la condición de miembro de la familia o si es necesario presentar otros documentos que lo acrediten.

El Tribunal de Justicia señaló en primer lugar que, aunque la disposición de la directiva relativa a la exención de la obligación de visado solo concede expresamente esta dispensa a los titulares de una tarjeta de residencia de familiar de un ciudadano de la Unión, esta circunstancia no demuestra por sí misma que el legislador de la Unión quisiera privar del disfrute de esa exención a los miembros de la familia de un ciudadano de la Unión que disponen de una tarjeta de residencia permanente. De un análisis global de la directiva resulta que los miembros de la familia de un ciudadano de la Unión que ya sean titulares de una tarjeta de residencia deben disfrutar de la exención en cuestión, ya que el legislador de la Unión quiso concedérsela a todos los miembros de la familia de un ciudadano de la Unión titulares de una tarjeta de residencia, con independencia de cuál sea el tipo de esta.

A este respecto, el Tribunal de Justicia destaca que la tarjeta de residencia permanente sólo puede expedirse a favor de quienes ya hayan obtenido una tarjeta de residencia de familiar de un ciudadano de la Unión y hayan residido legalmente con dicho ciudadano en el Estado miembro de acogida durante un período continuado de cinco años consecutivos, disfrutando durante ese tiempo de la exención de visado ligada a la posesión de dicha tarjeta. Esta apreciación se conforma a la finalidad de la directiva que es garantizar la integración gradual en la sociedad del Estado miembro de acogida de los ciudadanos de la Unión y de los miembros de su familia que no tengan la nacionalidad de un Estado miembro. La consecución de este objetivo se vería amenazada si la adquisición de un derecho de residencia permanente por parte de los miembros de la familia de un ciudadano de la Unión conllevara la pérdida de la exención de la obligación de obtener un visado de la que disfrutaban antes de adquirir ese derecho de residencia permanente. Por consiguiente, el Tribunal de Justicia estimó que el miembro de la familia de un ciudadano de la Unión que no tiene la nacionalidad de un Estado miembro, pero que es titular de una tarjeta de residencia permanente, está exento de la obligación de obtener un visado para entrar en el territorio de los Estados miembros.

A continuación, la sentencia precisó que la directiva se aplica indistintamente al conjunto de los Estados miembros, con independencia de que formen parte o no del espacio Schengen, y que su disposición relativa a la exención de visado no contiene ninguna referencia específica a este espacio. De lo anterior se desprende que pueden gozar de la exención de la obligación de obtener un visado prevista por la directiva los familiares de un ciudadano de la Unión titulares de una tarjeta de residencia o de una tarjeta de residencia permanente, tanto si esa tarjeta ha sido expedida por 
un Estado miembro que no forma parte del espacio Schengen, como si lo ha sido por un Estado miembro que sí forma parte del mismo.

Por último, el Tribunal de Justicia observó que, con arreglo a la directiva, los Estados miembros solo pueden expedir una tarjeta de residencia permanente a favor de las personas que tengan la condición de miembro de la familia de un ciudadano de la Unión. Así pues, la expedición de esa tarjeta por un Estado miembro implica que este ha tenido que comprobar necesariamente con antelación que la persona de que se trata reúne esta condición. Por consiguiente, una tarjeta de residencia permanente justifica por sí misma la condición de familiar de un ciudadano de la Unión de su titular. Por esta razón, el titular de una tarjeta de ese tipo tiene derecho a entrar en el territorio de un Estado miembro sin necesidad de comprobación o certificación adicional alguna de su condición de miembro de la familia de un ciudadano de la Unión.

El empleador de los conductores de vehículos de transporte internacional por carretera que trabajan por cuenta ajena es la empresa de transporte que ejerce el poder de dirección efectivo sobre dichos conductores, por cuya cuenta corren los gastos salariales y que dispone de la facultad efectiva para despedirlos (Sentencia de 16 de julio de 2020, AFMB, C-610/18, EU:C:2020:565).

Mediante esta sentencia, el Tribunal de Justicia, en formación de Gran Sala, declaró que el empleador de un conductor de vehículos de transporte internacional por carretera, con arreglo al Reglamento 1408/71 del Consejo, relativo a la aplicación de los regímenes de seguridad social a los trabajadores por cuenta ajena, a los trabajadores por cuenta propia y a los miembros de sus familias que se desplazan dentro de la Comunidad, en su versión modificada y actualizada, y al Reglamento 883/2004 del Parlamento Europeo y del Consejo, es la empresa que ejerce el poder de dirección efectivo sobre dicho conductor, por cuya cuenta corren de hecho los correspondientes costes salariales y que dispone de la facultad efectiva para despedirlo, y no la empresa con la que el conductor ha celebrado un contrato de trabajo y que figura formalmente en ese contrato como empleador del conductor.

En el litigio principal, AFMB Ltd, una sociedad establecida en Chipre, había celebrado con diversas empresas de transporte establecidas en los Países Bajos contratos en virtud de los cuales, a cambio de una comisión, se comprometía a gestionar por cuenta y riesgo de dichas empresas los vehículos de transporte de mercancías que estas explotaban. Asimismo, había celebrado contratos de trabajo con conductores de vehículos de transporte internacional por carretera residentes en los Países Bajos, conforme a cuyos términos era 
designada como su empleador. Dichos conductores ejercían su actividad por cuenta de las empresas de transporte en dos o más Estados miembros.

AFMB y los conductores impugnaban las resoluciones del Órgano Gestor de la Tesorería de la Seguridad Social de los Países Bajos, con arreglo a las cuales se había declarado aplicable a estos conductores la legislación neerlandesa en materia de seguridad social. En efecto, la administración neerlandesa había estimado que únicamente las empresas de transporte establecidas en los Países Bajos debían ser calificadas como empleadores de dichos conductores y que, por tanto, estos estaban sometidos a la legislación neerlandesa, mientras que AFMB y los conductores consideraban que era AFMB la que debía ser calificada como empleador y que, dado que su domicilio social se encuentra en Chipre, la legislación aplicable era la chipriota.

En tal contexto, el órgano jurisdiccional remitente, subrayando la importancia decisiva de esta cuestión para determinar la legislación nacional de seguridad social aplicable, solicitó al Tribunal de Justicia que aportara aclaraciones acerca de si es a las empresas de transporte o a AFMB a quien se debe atribuir la calificación de «empleador» de los conductores en cuestión. En efecto, en virtud de los reglamentos 1408/71 y 883/2004, las personas que, como en el caso de los conductores de que se trata, ejercen su actividad en dos o más Estados miembros sin estar ocupadas de forma preponderante en el territorio del Estado miembro en que residen, están sometidas, en materia de seguridad social, a la legislación del Estado miembro en el que el empleador tenga su sede o domicilio.

En primer lugar, el Tribunal de Justicia observó que sendos reglamentos no efectúan ninguna remisión a las legislaciones o a las prácticas nacionales con el fin de determinar el significado de los conceptos de «empleador» y de «personal». En consecuencia, procedía efectuar una interpretación autónoma y uniforme de estos conceptos, que tome en consideración no solo su tenor, sino también el contexto de las disposiciones pertinentes y el objetivo que la normativa de que se trata pretende alcanzar.

Por cuanto concierne a los términos utilizados y al contexto, el Tribunal de Justicia ha señalado, por una parte, que la relación entre el «empleador» y su "personal» implica una relación de subordinación entre ellos. Por otra parte, ha puesto de relieve que se debe tener en cuenta la situación objetiva en la que se encuentre el trabajador y el conjunto de circunstancias de su ocupación. A este respecto, si bien la celebración de un contrato de trabajo puede ser un indicador de una relación de subordinación, dicha circunstancia no permite por sí misma establecer de manera concluyente que tal relación exista. Se debe tomar en consideración, además de la información que contiene formalmente el contrato de trabajo, la manera en que se ejecutan en la práctica las obligaciones que incumben al trabajador y a la empresa en cuestión en el marco 
de ese contrato. Así pues, con independencia del tenor de los documentos contractuales, procede identificar la entidad que ejerce el poder de dirección efectivo sobre el trabajador, por cuya cuenta corren de hecho los correspondientes costes salariales y que dispone de la facultad efectiva de despedir al trabajador.

Según el Tribunal de Justicia, una interpretación que se fundase únicamente en consideraciones formales, como la celebración de un contrato de trabajo, equivaldría a permitir que las empresas desplacen el lugar que debe considerarse pertinente para determinar la legislación nacional de seguridad social aplicable, sin que, en realidad, ese desplazamiento se integre en el objetivo de garantizar el ejercicio efectivo de la libre circulación de los trabajadores perseguido por los reglamentos.

Por consiguiente, en lo que concierne el presente asunto, el Tribunal de Justicia señaló que aparentemente durante el período en cuestión los conductores formaron parte del personal de las empresas de transporte y estas eran sus empleadores, por lo que la legislación que les es aplicable parece ser la neerlandesa, extremo que, no obstante, corresponde verificar al órgano jurisdiccional remitente. En efecto, dichos conductores con anterioridad a la celebración de los contratos de trabajo con AFMB habían sido seleccionados por las propias empresas de transporte y tras la celebración de tales contratos ejercieron su actividad profesional por cuenta y riesgo de esas empresas. Asimismo, el coste efectivo de sus salarios era asumido, mediante la comisión abonada a AFMB, por las empresas de transporte. Por último, dichas empresas aparentemente disponían de la facultad efectiva de despido y una parte de los conductores ya formaban parte de su personal antes de que se celebraran los contratos de trabajo con AFMB.

La prohibición general de discriminación por razón de la nacionalidad no puede ser invocada a efectos de impugnar una cláusula, establecida en un contrato celebrado entre un fabricante de productos sanitarios y una entidad aseguradora, que limita el ámbito territorial de la cobertura del seguro de responsabilidad civil, por cuanto tal situación no está comprendida, en el estado actual del derecho de la Unión, dentro de su ámbito de aplicación (Sentencia de 11 de junio de 2020, TÜV Rheinland, C-581/18, EU:C:2020:453).

En esta sentencia, el Tribunal de Justicia, reunido en Gran Sala, examinó la cuestión de si un contrato de seguro que contiene una cláusula que limita la cobertura del seguro a los daños producidos en Francia es contraria a la prohibición de discriminación por razón de la nacionalidad, establecida en el art. 18 TFUE, párr. primero. 
La demandante en el litigio principal era una ciudadana alemana, residente en Alemania, que se sometió en 2006 en este Estado miembro a una intervención de implantación de prótesis mamarias fabricadas por Poly Implant Prothèses SA (PIP), sociedad con domicilio social en Francia. A partir de octubre de 1997, PIP había solicitado a TÜV Rheinland, con arreglo a lo dispuesto en la Directiva 93/42 del Consejo, relativa a los productos sanitarios, que procediera a la evaluación del sistema de calidad establecido para el diseño, la fabricación y el control final de los implantes mamarios que producía. A raíz de diversas inspecciones efectuadas en PIP, TÜV Rheinland aprobó el sistema de calidad y renovó los certificados de examen CE, garantizando de ese modo la conformidad de dichos implantes con las exigencias de la Directiva. Por otro lado, PIP había suscrito un contrato de seguro que cubría su responsabilidad civil por la producción de esos implantes. Dicho contrato contenía una cláusula que limitaba el ámbito territorial de la cobertura del seguro a los daños producidos en Francia.

En 2010, la Agence française de sécurité sanitaire des produits de santé (Agencia Francesa de Seguridad de los Productos Sanitarios) constató que los implantes mamarios fabricados por PIP estaban rellenos de silicona industrial no autorizada. Por otro lado, en 2012, el Instituto Federal de Medicamentos y Productos Sanitarios en Alemania recomendó a las pacientes afectadas que, con carácter preventivo, les fueran retirados los implantes fabricados por PIP a causa del riesgo de ruptura prematura y de la posibilidad de que la silicona utilizada produjera una inflamación.

La paciente de que se trata presentó, ante el órgano jurisdiccional alemán competente, una demanda de indemnización por daños y perjuicios dirigida conjunta y solidariamente contra el médico que le había colocado los implantes mamarios defectuosos y contra TÜV Rheinland y la aseguradora del contrato de seguro suscrito por PIP. En particular, alegó que el derecho francés le confiere el derecho de ejercitar una acción directa contra la aseguradora, aun cuando el contrato de seguro contenga una cláusula que limita la cobertura del seguro a los daños producidos en Francia, dado que, a su juicio, dicha cláusula es contraria al derecho de la Unión.

El Tribunal de Justicia examinó, con carácter previo, si el art. 18 TFUE, párrafo primero, es aplicable. A este respecto, recordó que, según reiterada jurisprudencia, la aplicación de esta disposición está subordinada al cumplimiento de dos requisitos acumulativos, en primer lugar, que la situación que haya dado origen a la discriminación invocada esté comprendida en el ámbito de aplicación del derecho de la Unión y, en segundo lugar, que no sea aplicable a tal situación ninguna norma específica establecida en los tratados y dirigida a prohibir una discriminación por razón de la nacionalidad. 
A fin de apreciar si en este caso concreto concurría el primer requisito, el Tribunal de Justicia analizó, en primer lugar, si la situación objeto del litigio principal ha sido objeto de regulación en el derecho de la Unión. Ha constatado que en el derecho derivado no existe ninguna disposición que establezca la obligación de los fabricantes de productos sanitarios de suscribir un seguro de responsabilidad civil que cubra los riesgos derivados de estos productos o que regule tal seguro. El Tribunal de Justicia concluyó que, en el estado actual del derecho de la Unión, el seguro de responsabilidad civil de los fabricantes de productos sanitarios por los daños inherentes a dichos productos no es objeto de regulación por este derecho.

En segundo lugar, el Tribunal de Justicia examinó si la situación de que se trata está comprendida en el ámbito de aplicación de una libertad fundamental establecida por el Tratado FUE, por existir un vínculo concreto entre esta situación y tal libertad, que permita incluirla en el ámbito de aplicación de los tratados, con arreglo al art. 18 TFUE, párr. primero.

En cuanto concierne, en primer lugar, a la libre circulación de los ciudadanos de la Unión, el Tribunal de Justicia señaló que la paciente de que se trata no hizo uso de su libertad de circulación, dado que solicita una indemnización del seguro por los daños que sufrió a raíz de la implantación de prótesis mamarias en el Estado miembro en el que reside, de modo que no existe ningún vínculo concreto entre la situación objeto del litigio principal y esta libertad. A continuación, respecto a la libre prestación de servicios, el Tribunal de Justicia observó que tal situación tampoco presenta un vínculo concreto con esta libertad, puesto que, por una parte, la paciente recibió cuidados médicos en su Estado miembro de residencia y, por otra parte, el contrato de seguro en cuestión fue concluido entre dos sociedades establecidas en un mismo Estado miembro, concretamente en Francia. Por último, respecto a la libre circulación de mercancías, el Tribunal de Justicia señaló que la circulación transfronteriza de los implantes mamarios en cuestión no se había visto afectada por ningún obstáculo discriminatorio, sino a los daños causados por las mercancías objeto de tal circulación. Por consiguiente, para el Tribunal de Justicia la situación que planteó el litigio principal no estaba comprendida dentro del ámbito de aplicación del derecho de la Unión, con arreglo al art. 18 TFUE, párr. primero, por lo que procede excluir la aplicación de esta disposición al presente asunto.

Las restricciones impuestas por Hungría a la financiación de las organizaciones civiles por parte de personas domiciliadas fuera de dicho Estado miembro no son conformes con el derecho de la Unión (Sentencia de 18 de junio de 2020, Comisión/Hungría, C-78/18, EU:C:2020:476). 
Mediante esta sentencia, la Gran Sala del Tribunal de Justicia estimó el recurso por incumplimiento interpuesto por la Comisión Europea contra Hungría y declaró que, al imponer obligaciones de registro, de declaración y de publicidad a ciertas categorías de organizaciones de la sociedad civil que reciben directa o indirectamente ayuda del extranjero por encima de un determinado importe y al contemplar la posibilidad de aplicar sanciones a las organizaciones que incumplan tales obligaciones, Hungría estableció restricciones discriminatorias e injustificadas tanto respecto de las organizaciones en cuestión como de las personas que les conceden tal ayuda. Estas restricciones chocan con las obligaciones que incumben a los Estados miembros en virtud de la libre circulación de capitales establecida en el art. 63 TFUE y de los arts. 7, 8 y 12 de la Carta de los Derechos Fundamentales de la Unión Europea, relativos al derecho al respeto de la vida privada y familiar, al derecho a la protección de datos de carácter personal y al derecho a la libertad de asociación.

Los hechos se remontan a 2017, cuando Hungría adoptó una ley presentada como una ley dirigida a garantizar la transparencia de las organizaciones civiles que reciben donaciones procedentes del extranjero. A tenor de dicha ley, estas organizaciones deben registrarse ante los órganos jurisdiccionales húngaros como "organizaciones receptoras de ayuda extranjera» desde el momento en que el importe de las donaciones que reciben en un año procedentes de otros Estados miembros o de países terceros supere un determinado importe. Al registrarse deben indicar también, entre otras cosas, el nombre de los donantes cuya ayuda alcance o supere la suma de 500000 forintos húngaros (unos 1400 euros) y el importe exacto de la ayuda. A continuación, esta información se publica en una plataforma electrónica pública, accesible gratuitamente. Además, las organizaciones civiles afectadas deben mencionar, en su página web de bienvenida y en todas sus publicaciones, que son una "organización receptora de ayuda extranjera». La Comisión interpuso un recurso por incumplimiento ante el Tribunal de Justicia contra Hungría, al considerar que dicha ley infringía tanto el Tratado como la Carta.

En cuanto al fondo, el Tribunal de Justicia declaró, con carácter preliminar, que Hungría carecía de fundamento para imputar a la Comisión que no hubiese aportado pruebas de los efectos prácticos de la Ley de transparencia en la libertad de circulación garantizada en el art. 63 TFUE. En efecto, la existencia de un incumplimiento puede probarse, en caso de que tenga su origen en la adopción de una medida legislativa o reglamentaria cuya existencia y aplicación no se niegan, mediante un análisis jurídico de las disposiciones de tal medida.

Al examinar a continuación si las alegaciones de la Comisión resultaban fundadas, el Tribunal de Justicia declaró, en primer lugar, que las operaciones 
cubiertas por la ley de transparencia estaban comprendidas en el concepto «movimientos de capitales» que figura en el art. 63 TFUE, apdo. 1, y que la ley en cuestión constituía una medida restrictiva, de carácter discriminatorio, porque establece una diferencia de trato entre los movimientos nacionales y transfronterizos de capitales que no se explica por ninguna diferencia objetiva entre las situaciones de que se trata y que puede disuadir a las personas físicas o jurídicas domiciliadas en otros Estados miembros o en países terceros de prestar ayuda económica a las organizaciones afectadas. En particular, la ley de transparencia húngara se aplica, de forma específica y exclusiva, a las asociaciones y fundaciones que reciben ayuda extranjera procedente de otros Estados miembros o de países terceros, a las que la referida ley singulariza obligándolas a que se declaren, se registren y se presenten sistemáticamente al público bajo la denominación de "organizaciones receptoras de ayuda extranjera», so pena de sanciones que pueden llegar incluso a su disolución. Además, las medidas que establece pueden crear un clima de desconfianza hacia estas asociaciones y fundaciones. Por lo demás, la divulgación pública de información relativa a las personas domiciliadas en otros Estados miembros o en países terceros que conceden tal ayuda económica a esas mismas asociaciones y fundaciones puede disuadirlas de proporcionar tal ayuda. En consecuencia, las obligaciones de registro, de declaración y de publicidad, así como las sanciones previstas por la ley de transparencia, constituyen, consideradas conjuntamente, una restricción a la libre circulación de capitales, prohibida por el art. 63 TFUE.

En cuanto a la posible justificación de esta restricción, el Tribunal de Justicia destacó que el objetivo de aumentar la transparencia de la financiación de las asociaciones puede considerarse una razón imperiosa de interés general. En efecto, determinadas organizaciones de la sociedad civil pueden tener, en vista de los fines que persiguen y de los medios de que disponen, una influencia notable en la vida y el debate públicos que justifique que su financiación se someta a medidas dirigidas a garantizar la transparencia, en particular cuando tal financiación procede de países de fuera de la Unión. No obstante, en el presente asunto, Hungría no acreditó por qué el objetivo de aumentar la transparencia de la financiación de las asociaciones que invocaba justificaba las medidas concretamente establecidas por la ley de transparencia. En particular, estas se aplican de forma indiferenciada respecto de toda ayuda económica extranjera que supere un determinado importe y a todas las organizaciones comprendidas en el ámbito de aplicación de dicha ley, en vez de centrarse en aquellas que puedan tener realmente una influencia notable en la vida y el debate públicos.

Por lo que respecta a las razones de orden público y de seguridad pública mencionadas en el art. 65 TFUE, apdo. 1, letra b), el Tribunal de Justicia recordó que tales razones pueden ser invocadas en un ámbito concreto 
siempre que el legislador de la Unión no haya llevado a cabo la armonización completa de las medidas dirigidas a garantizar su protección, y que dichas razones incluyen, entre otras, la lucha contra el blanqueo de capitales, la financiación del terrorismo y la delincuencia organizada. No obstante, estas razones solo son admisibles en presencia de una amenaza real, actual y suficientemente grave que afecte a un interés fundamental de la sociedad. Pues bien, en el presente asunto, Hungría no aportó ningún argumento que pudiera demostrar, de forma concreta, una amenaza de tales características. La ley de transparencia se basa más bien en una presunción de principio e indiferenciada según la cual toda financiación extranjera de las organizaciones civiles es intrínsecamente sospechosa. Por consiguiente, el Tribunal de Justicia concluyó que las restricciones derivadas de la ley de transparencia no estaban justificadas y de que, por tanto, Hungría había incumplido las obligaciones que le incumbían en virtud del art. 63 TFUE.

En segundo lugar, el Tribunal de Justicia examinó si las disposiciones de la ley de transparencia eran conformes con los arts. 7, 8 y 12 de la Carta, con la cual debe ser conforme una medida nacional cuando el Estado miembro autor de dicha medida pretenda justificar mediante una razón imperiosa de interés general o una razón mencionada por el TFUE la restricción que tal medida supone.

Por lo que respecta al derecho a la libertad de asociación, consagrado en el art. 12, apdo. 1, de la Carta, el Tribunal de Justicia destacó que constituye uno de los fundamentos esenciales de una sociedad democrática y pluralista, ya que permite a los ciudadanos actuar colectivamente en ámbitos de interés común y contribuir, de ese modo, al buen funcionamiento de la vida pública. En el presente asunto, el Tribunal de Justicia declaró que las medidas establecidas por la ley de transparencia limitaban dicho derecho, en la medida en que dificultaban significativamente, en varios aspectos, la acción y el funcionamiento de las asociaciones comprendidas en el ámbito de aplicación de esta ley.

A continuación, en cuanto al derecho al respeto de la vida privada y familiar consagrado en el art. 7 de la Carta, el Tribunal de Justicia recordó que los poderes públicos están obligados a abstenerse de toda injerencia injustificada en la vida de las personas. En el presente asunto, señaló que las obligaciones de declaración y de publicidad establecidas en la ley de transparencia limitaban este derecho. Por lo que respecta al derecho a la protección de los datos de carácter personal consagrado en el art. 8, apdo. 1, de la Carta, que está vinculado, en cierta medida, al derecho al respeto de la vida privada y familiar, el Tribunal de Justicia recordó que dicho derecho se opone a que se difunda a terceros información relativa a personas físicas identificadas o identificables, ya sean esos terceros autoridades públicas o el público en 
general, salvo que dicha difusión se produzca en virtud de un tratamiento leal que responda a las exigencias establecidas en el art. 8, apdo. 2, de la Carta. Así pues, excepto en ese supuesto, debe considerarse que la referida difusión, que constituye un tratamiento de datos de carácter personal, limita el derecho a la protección de datos de carácter personal garantizado en el art. 8, apdo. 1, de la Carta. Pues bien, en el presente asunto, la ley de transparencia contemplaba la divulgación de datos de carácter personal y Hungría no alegó que tal divulgación se produjese en el marco de un tratamiento que respondiese a las exigencias mencionadas.

Abordando, por último, la cuestión de la posible justificación de las limitaciones de los derechos fundamentales, el Tribunal de Justicia señaló que las disposiciones de la ley de transparencia no podían justificarse con ninguno de los objetivos de interés general invocados por Hungría, como se derivaba del análisis ya realizado a la luz del TFUE.

\section{COMPETENCIA}

Un requerimiento de suspensión provisional de la ejecución de unas ayudas de Estado en curso, pendiente la investigación formal de las mismas, debe contener las razones por las que la Comisión considera que el Estado miembro de que se trate no suspendería las medidas en cuestión pese a la incoación del procedimiento de investigación formal (Sentencia de 4 de junio de 2020, Hungría/Comisión, C-456/18 P, EU:C:2020:421).

Mediante esta sentencia, a raíz de un recurso de casación presentado por Hungría contra una sentencia del Tribunal General de 25 de abril de 2018 (T-554/15 y T-555/15, EU:T:2018:220) en la que el Tribunal General desestimó su recurso de anulación contra dos requerimientos de suspensión provisional de unas ayudas en curso para los que la Comisión incoó un procedimiento de investigación formal al amparo del art. 108 TFUE, apdo. 2, el Tribunal de Justicia tuvo la oportunidad de ocuparse de la tutela judicial frente a estos requerimientos de suspensión provisional aisladamente considerados.

Dichos requerimientos prohibían explícitamente a Hungría seguir ejecutando dos ayudas mientras no finalizara el procedimiento de investigación. Se trataba de unas leyes fiscales húngaras que introducían la aplicación del tipo impositivo progresivo, respectivamente, de la contribución sanitaria de las empresas del sector del tabaco (sobre el volumen de negocios anual de las empresas que obtuvieran al menos el $50 \%$ de su volumen de negocios de la producción o de la comercialización de las labores de tabaco) y de la tasa 
de inspección de la cadena alimentaria (sobre el volumen de negocios de las entidades que comercializan bienes de consumo corriente).

El Tribunal de Justicia primero recordó que el art. 108 TFUE, apdo. 3, ya establece que los Estados miembros no pueden ejecutar la medida de ayuda en cuestión una vez incoado el procedimiento de investigación. Sin embargo, un requerimiento de suspensión provisional —en la práctica no demasiado común - permite a la Comisión incoar un procedimiento por incumplimiento simplificado, si el Estado miembro aun así ejecuta la medida. No obstante, la incoación del procedimiento de investigación formal contra una medida no notificada no acarrea las mismas consecuencias para el Estado miembro interesado que la adopción de un requerimiento de suspensión. Es cierto que dicho Estado miembro tiene la obligación, en ambas hipótesis, de suspender la ejecución de la medida en cuestión. Sin embargo, solo el incumplimiento de un requerimiento de suspensión permite a la Comisión interponer un recurso directamente ante el Tribunal de Justicia para que se declare el incumplimiento.

El Tribunal de Justicia procedió a examinar si los dos requerimientos de suspensión de la aplicación de las dos leyes húngaras controvertidas cumplían con los requisitos de proporcionalidad y motivación. Por lo que respecta la proporcionalidad del requerimiento, el Tribunal de Justicia observó que en virtud de este principio un requerimiento de suspensión no debe rebasar los límites de lo que resulta adecuado y necesario para el logro del objetivo perseguido por dicha disposición.

De esta manera, la adopción de un requerimiento de suspensión está justificada si, una vez iniciado el procedimiento de investigación formal, el Estado miembro interesado no procede a suspender la aplicación de la medida examinada. No obstante, puede resultar igualmente adecuado adoptar un requerimiento de suspensión simultáneamente a la decisión de incoar el procedimiento de investigación formal en la hipótesis de que concurran circunstancias suficientes que permitan a la Comisión presumir que el Estado miembro interesado no tiene intención de suspender la ejecución de la medida examinada pese a estar obligado a ello a raíz de la incoación del procedimiento de investigación formal y anticipar que va a ser necesario, por tanto, interponer un recurso por incumplimiento ante el Tribunal de Justicia. El Tribunal de Justicia consideró, al respecto, que el Tribunal General analizó correctamente que la Comisión había observado el principio de proporcionalidad.

En cuanto al deber de motivación de sendas decisiones, el Tribunal de Justicia señaló que, en caso de un requerimiento de suspensión provisional, son necesarios motivos particulares que conduzcan a la institución a adoptar tal decisión. En efecto, la obligación de motivación de los actos de las instituciones determina que los motivos de toda decisión deben ponerse 
en conocimiento de su destinatario, con el fin de que este pueda apreciar su conformidad a derecho y ejercer, en su caso, su derecho de recurso con las garantías debidas. La exposición de los motivos se impone también para que el juez de la Unión pueda controlar la legalidad del requerimiento de suspensión a la luz del principio de proporcionalidad y verificar que la Comisión no ha hecho un uso injustificado de la facultad de adoptar los requerimientos en cuestión. De esta manera, la decisión por la que se adopta tal requerimiento debe permitir comprender por qué, según la Comisión, el Estado miembro interesado no iba a respetar la obligación derivada del art. 108 TFUE, apdo. 3 , y a suspender la ejecución de las medidas examinadas a raíz de la incoación del procedimiento de investigación formal.

El Tribunal de Justicia concluyó que, debido a que sendas decisiones no explicaban las razones por las que consideraba que Hungría no suspendería las medidas en cuestión pese a la incoación del procedimiento de investigación formal, los requerimientos adolecían de una motivación insuficiente y debían ser anulados. Al respecto, el hecho de que Hungría no hubiera formulado alegaciones relativas a un posible requerimiento de suspensión no bastaba para justificar el temor de la Comisión de que el citado Estado miembro ejecutara las medidas controvertidas.

En el marco de un régimen nacional de seguro de enfermedad que se basa en el principio de solidaridad, las entidades de seguro públicas que prestan este servicio no se consideran «empresas» en el ámbito del artículo 107 TFUE, apartado 1, aunque coexistan ciertos elementos competitivos en el contexto de dicho régimen con entidades privadas, si dichos elementos competitivos del régimen tienen carácter secundario respecto de sus elementos sociales, solidarios y reglamentarios, y la posibilidad que se ofrece a las entidades aseguradoras de perseguir, utilizar y distribuir beneficios está estrictamente delimitada por obligaciones legales que tienen como finalidad preservar la viabilidad y la continuidad del seguro de enfermedad obligatorio (Sentencia de 11 de junio de 2020, Comisión y Eslovaquia/Dôvera, asuntos acumulados C-262/18 P y C-271/18 P, EU:C:2020:450).

En esta sentencia el Tribunal de Justicia se pronunció sobre la inaplicación de las normas en materia de ayudas de Estado a las entidades del seguro de enfermedad que operan bajo el control del Estado en el marco de un régimen de seguridad social que persigue un objetivo social y aplica el principio de solidaridad. En formación de Gran Sala, el Tribunal estimó dos recursos de casación presentados, respectivamente, por Eslovaquia y por la Comisión, y anuló la sentencia del Tribunal General de 5 de febrero de 
2018 (T-216/15, EU:T:2018:64), y, pronunciándose definitivamente sobre el litigio, desestimó en su totalidad el recurso de anulación interpuesto en su día por una entidad eslovaca del seguro de enfermedad privada contra una decisión en la que la Comisión concluyó que otras dos entidades del seguro de enfermedad eslovaco no habían recibido ayuda de Estado con arreglo al art. 107 TFUE, apdo. 1, porque no se consideran «empresas» en el sentido de ese artículo.

En 1994, el régimen eslovaco del seguro de enfermedad pasó de ser un sistema unitario, con una única entidad pública de seguro de enfermedad, a ser un modelo mixto, en el que pueden coexistir entidades públicas y privadas. De esta forma, los residentes eslovacos podían elegir entre varias entidades del seguro de enfermedad, cuyo único accionista era el Estado eslovaco, por una parte, o cuyos accionistas eran entidades del sector privado, por otra parte. En la decisión controvertida la Comisión consideró, sin embargo, que la actividad ejercida por las entidades de seguro públicas no era de naturaleza económica y que, por consiguiente, dichas entidades no eran empresas en el sentido del art. 107 TFUE, apdo. 1, por lo que las medidas denunciadas no podían constituir ayudas de Estado. El Tribunal General estimó el recurso de anulación interpuesto por una entidad de seguros privada (Dôvera) contra esta decisión, al considerar, en particular, que la Comisión no había aplicado correctamente los conceptos de «empresa», en el sentido del art. 107 TFUE, apdo. 1, y de «actividad económica».

El Tribunal de Justicia recordó, de entrada, que la prohibición de otorgar ayudas de Estado establecida en el art. 107 TFUE, apdo. 1, se refiere únicamente a las actividades de las empresas, concepto este último que comprende cualquier entidad que ejerza una actividad económica, con independencia del estatuto jurídico de dicha entidad y de su modo de financiación. Pues bien, al afirmar que la actividad ejercida por las entidades de seguro públicas en el marco del régimen eslovaco del seguro de enfermedad obligatorio cuyas características corresponden a las de un régimen de seguridad social que persigue un objetivo social y aplica el principio de solidaridad bajo el control del Estado- presenta carácter económico, el Tribunal General incurrió en varios errores de derecho.

Para evaluar si una actividad ejercida en el marco de un régimen de seguridad social carece de carácter económico, es preciso verificar, en particular, si, y en qué medida, puede considerarse que dicho régimen aplica el principio de solidaridad y si la actividad de las entidades aseguradoras que gestionan ese régimen está sometida al control del Estado. Al respecto, el Tribunal de Justicia señaló que, en contra de lo afirmado por el Tribunal General, la existencia de un cierto grado de competencia en cuanto a la calidad y a la amplitud de la oferta en el régimen eslovaco del seguro de enfermedad 
obligatorio — como la posibilidad de que disponen las entidades aseguradoras de ofrecer a los afiliados prestaciones complementarias a título gratuito y la libertad de los afiliados de elegir la entidad de seguro de enfermedad a la que desean afiliarse y de cambiar de entidad una vez al año-, no pone en entredicho la naturaleza social y solidaria de la actividad llevada a cabo por las entidades aseguradoras en el marco de un régimen que aplica el principio de solidaridad bajo el control del Estado.

Por añadidura, el Tribunal de Justicia observó que la afiliación al régimen eslovaco del seguro de enfermedad es obligatoria para todos los residentes eslovacos, que el importe de las cotizaciones se fija por ley en proporción a los ingresos de las personas afiliadas y no al riesgo que representan debido a su edad o a su estado de salud, y que todos los afiliados tienen derecho a un mismo nivel de prestaciones establecido por ley, de modo que no existe un vínculo directo entre el importe de las cotizaciones abonadas por los afiliados y las prestaciones que reciben. Además, las entidades aseguradoras están obligadas a garantizar la cobertura del riesgo de enfermedad de todo residente eslovaco que lo solicite, con independencia de las contingencias derivadas de su edad o de estado de salud, y el referido régimen también prevé un mecanismo de compensación de costes y riesgos. Así pues, según el Tribunal de Justicia, este régimen de seguro presenta todas las características del principio de solidaridad. Tras declarar que el régimen eslovaco del seguro de enfermedad obligatorio está igualmente sujeto al control del Estado, el Tribunal de Justicia observó asimismo que la presencia de elementos competitivos en el contexto de este régimen tiene carácter secundario respecto de sus elementos sociales, solidarios y reglamentarios, y que la posibilidad que se ofrece a las entidades aseguradoras de perseguir, utilizar y distribuir beneficios está estrictamente delimitada por obligaciones legales que tienen como finalidad preservar la viabilidad y la continuidad del seguro de enfermedad obligatorio. Habida cuenta de estas consideraciones, el Tribunal de Justicia estimó que la Comisión actuó fundadamente al concluir, en la decisión controvertida, que el régimen eslovaco del seguro de enfermedad obligatorio persigue un objetivo social y aplica el principio de solidaridad bajo el control del Estado y, por lo tanto, la actividad de las dos entidades de seguro públicas en el marco de dicho régimen no tenía naturaleza económica, y al declarar, en consecuencia, que dichas entidades no podían ser calificadas de empresas en el sentido del art. 107 TFUE, apdo. 1.

El Tribunal de Justicia confirma que la Comisión puede en determinados casos realizar copia de determinados datos informáticos durante una inspección, llevarlos a las oficinas de la Comisión en Bruselas, y examinar en las mismas los datos en presencia de los representantes de 


\section{las empresas inspeccionadas (Sentencia de 16 de julio de 2020, Nexans France y Nexans/Comisión, C-606/18 P, EU:C:2020:571).}

Mediante esta sentencia el Tribunal de Justicia desestimó el recurso de casación interpuesto por Nexans France y su sociedad matriz, Nexans, contra la sentencia del Tribunal General de 12 de julio de 2018 (T-449/14). El recurso de casación impugnaba, en particular, la interpretación del Tribunal General relativa al alcance de las facultades que el art. 20 del Reglamento (CE) 1/2003 del Consejo, relativo a la aplicación de las normas sobre competencia confiere a la Comisión en una inspección en materia de prácticas colusorias.

Las recurrentes, sociedades que operan en el sector de la fabricación y del suministro de cables de energía subterráneos y submarinos, fueron objeto de una decisión de la Comisión por la que se declaró una infracción del art. 101 TFUE en dicho sector. La investigación llevada a cabo por la Comisión que dio lugar a la imposición de esas multas incluía una inspección en los locales de las recurrentes. En ellos, los inspectores de la Comisión se centraron, en particular, en los ordenadores de determinados empleados. Realizaron una copia imagen de los discos duros de esos ordenadores y, a partir de ella, lanzaron una búsqueda por palabras clave en los datos contenidos en esos ordenadores, empleando para ello un programa de investigación informática. A continuación, los inspectores decidieron copiar datos seleccionados y grabarlos en soportes informáticos de almacenamiento de datos (SIAD). Realizaron igualmente tres copias imagen de un disco duro, que grabaron en tres SIAD distintos. Los SIAD se colocaron en sobres precintados y se llevaron a las oficinas de la Comisión en Bruselas. En ellas, se abrieron los sobres y se examinaron los SIAD en presencia de los representantes de las recurrentes.

El recurso de anulación fue desestimado en su totalidad. En apoyo de su recurso de casación contra dicha sentencia, las recurrentes invocaron cinco motivos, referentes, por un lado, a la desestimación por el Tribunal General de las alegaciones de aquellas sobre el desarrollo de la inspección de que se trata y, por otro lado, a la desestimación por el Tribunal General de la pretensión de las recurrentes de reducción de las multas que les habían sido impuestas.

El Tribunal de Justicia comenzó analizando, en el marco del primer motivo de casación, si la Comisión tenía derecho, durante la inspección llevada a cabo en los locales de las recurrentes, a realizar una copia imagen de un disco duro de ordenador y copias de series de correos electrónicos sin haber procedido previamente a un examen riguroso de estos elementos. Tras recordar que el legislador de la Unión ha concedido a la Comisión cierto margen de apreciación de las modalidades concretas del examen al que puede proceder, el Tribunal de Justicia confirmó que, según las circunstancias, esta institución puede decidir examinar los datos contenidos en un soporte digital 
de la empresa inspeccionada a partir de una copia de esos datos. El Tribunal de Justicia puntualizó que este derecho de la Comisión, dimanante del art. 20, apdo. 2, letra b), del Reglamento $1 / 2003$, no afecta ni a las garantías procedimentales ni a los demás derechos de la empresa inspeccionada, siempre que la Comisión, tras haber concluido su examen, solo incorpore al expediente documentación pertinente habida cuenta del objeto de la inspección. Al igual que el Tribunal General, el Tribunal de Justicia estimó que así se había hecho en el presente asunto. Añadió que, habida cuenta de que el tiempo necesario para tratar datos electrónicos puede resultar considerable, el hecho de que la Comisión se base, para efectuar su examen, en una copia de esos datos también redunda en beneficio de la empresa afectada, ya que ello permite que esta empresa pueda seguir utilizando los datos originales y los soportes en que se encuentran estos en cuanto se haya realizado su copia y reduce, en consecuencia, la injerencia causada en el funcionamiento de dicha empresa por la inspección llevada a cabo por la Comisión.

A continuación, en el marco de los motivos de casación segundo y tercero, el Tribunal de Justicia analizó si la Comisión tenía derecho a proseguir la inspección de que se trata en sus oficinas de Bruselas. A este respecto, recordó que obligar a la Comisión a tratar tales datos exclusivamente en los locales de la empresa inspeccionada cuando se trate de datos particularmente voluminosos podría prolongar considerablemente la duración de la presencia de los inspectores en los locales de esta empresa, lo que podría mermar la eficacia de la inspección y aumentar inútilmente la injerencia en el funcionamiento de dicha empresa en razón de la inspección. Con todo, el Tribunal de Justicia puntualizó que la Comisión solo puede hacer uso de la posibilidad de proseguir el examen de la documentación profesional de la empresa inspeccionada en sus oficinas de Bruselas cuando pueda considerar legítimamente que está justificado hacerlo en pro de la eficacia de la inspección o para evitar una injerencia excesiva en el funcionamiento de la empresa afectada. Además, el Tribunal de Justicia subrayó que esta posibilidad está supeditada a que se compruebe que la continuación del examen no supone vulneración alguna del derecho de defensa y no constituye una injerencia añadida en los derechos de las empresas afectadas. Una injerencia de esta índole se produciría si la continuación del examen en las oficinas de la Comisión en Bruselas entrañara para la empresa inspeccionada costes adicionales derivados únicamente de esa continuación. Por consiguiente, en el supuesto de que la continuación del examen pueda dar lugar a tales costes adicionales, la Comisión solo podrá proceder a ella si acepta reembolsar dichos costes cuando la empresa afectada le presente una solicitud debidamente motivada. 


\section{APROXIMACIÓN DE LEGISLACIONES}

Cuando una película se sube de manera ilegal a una plataforma en línea, como YouTube, su titular únicamente puede solicitar al operador, en virtud de la directiva relativa al respeto de los derechos de propiedad intelectual, la dirección postal del usuario de que se trate, pero no su dirección de correo electrónico, ni la dirección IP, ni su número de teléfono (Sentencia de 9 de julio de 2020, Constantin Film Verleih, C-264/19, EU:C:2020:542).

En esta sentencia, el Tribunal de Justicia ha declarado que, en el contexto de la subida de una película a una plataforma de vídeos en línea sin el consentimiento del titular de los derechos de autor, el art. 8, apdo. 2, letra a), de la Directiva 2004/48/CE del Parlamento Europeo y del Consejo, relativa al respeto de los derechos de propiedad intelectual, no obliga a que las autoridades judiciales ordenen al operador de la plataforma que proporcione la dirección de correo electrónico, la dirección IP o el número de teléfono del usuario que haya subido la película de que se trate. La directiva, que prevé que se faciliten las «direcciones» de las personas que hayan infringido un derecho de propiedad intelectual, se refiere únicamente a la dirección postal.

Dos películas fueron subidas a la plataforma de vídeos YouTube sin el consentimiento de Constantin Film Verleih, titular de los derechos exclusivos de explotación de dichas obras en Alemania. Por ello, Constantin Film Verleih solicitó a YouTube y a Google —esta última, sociedad matriz de la primera y en la que los usuarios deben registrarse en primer lugar con una cuenta de usuario- que le facilitaran una serie de datos sobre cada uno de los usuarios que habían puesto en línea las citadas obras. Ambas sociedades se negaron a facilitar a Constantin Film Verleih la información relativa a dichos usuarios, en particular, sus direcciones de correo electrónico y sus números de teléfono, así como las direcciones IP que estos habían utilizado tanto en el momento en que subieron los ficheros en cuestión como en el momento en que accedieron por última vez a sus cuentas de Google o YouTube. La solución del litigio dependía de la respuesta que se diera a la pregunta de si dicha información está comprendida en el concepto de "direcciones», en el sentido de la Directiva 2004/48. Esta directiva establece que las autoridades judiciales pueden ordenar que se faciliten datos sobre el origen y las redes de distribución de las mercancías o servicios que infringen un derecho de propiedad intelectual. Entre estos datos figuran, en particular, las «direcciones» de los productores, distribuidores y suministradores de las mercancías o de los servicios litigiosos. 
El Tribunal de Justicia ha declarado en primer lugar que, por lo que respecta al sentido habitual del término "dirección», este solo se refiere a la dirección postal, es decir, al lugar del domicilio o de la residencia de una persona determinada. De ello se deduce que, cuando se utiliza sin más precisiones, como ocurre en la Directiva 2004/48, este término no comprende la dirección de correo electrónico, el número de teléfono o la dirección IP. En segundo lugar, los trabajos preparatorios que condujeron a la adopción de la Directiva 2004/48 no contienen indicio alguno que sugiera que el término «dirección» deba entenderse en el sentido de que no solo se refiere a la dirección postal, sino también a la dirección de correo electrónico, al número de teléfono o a la dirección IP de las personas de que se trate. En tercer lugar, el examen de otros actos de derecho de la Unión relativos a la dirección de correo electrónico o a la dirección IP pone de manifiesto que ninguno de ellos utiliza el término «dirección», sin más precisiones, para designar el número de teléfono, la dirección IP o la dirección de correo electrónico.

Según el Tribunal de Justicia, esta interpretación es conforme con la finalidad perseguida por la disposición de la Directiva 2004/48 relativa al derecho de información. En efecto, habida cuenta de la armonización mínima relativa al respeto de los derechos de propiedad intelectual en general, esta armonización se limita, según dicha disposición, a datos bien determinados. Por otra parte, esta disposición pretende conciliar el respeto de diferentes derechos, en particular el derecho de información de los titulares y el derecho a la protección de los datos personales de los usuarios.

Sin embargo, el Tribunal de Justicia ha precisado que los Estados miembros tienen la facultad de conceder a los titulares de derechos de propiedad intelectual el derecho a recibir una información más amplia, con la condición, no obstante, de que se garantice un justo equilibrio entre los distintos derechos fundamentales de que se trate y el respeto a otros principios generales del derecho de la Unión, como el principio de proporcionalidad.

La protección del derecho de autor se aplica a un producto cuya forma es, al menos parcialmente, necesaria para la obtención de un resultado técnico cuando ese producto constituye una obra original resultante de una creación intelectual, ya que, por medio de esa forma, su autor expresa su capacidad creativa de manera original adoptando decisiones libres y creativas de modo que la citada forma refleja su personalidad (Sentencia de 11 de junio de 2020, Brompton Bicycle, C-833/18, EU:C:2020:461).

La petición de decisión prejudicial tenía por objeto la interpretación de la Directiva 2001/29/CE del Parlamento Europeo y del Consejo, relativa a la 
armonización de determinados aspectos de los derechos de autor y derechos afines a los derechos de autor en la sociedad de la información, y se presentaba en el contexto de un litigio entre, por un lado, SI y Brompton Bicycle Ltd (Brompton) y, por otro lado, Chedech/Get2Get (Get2Get) en relación con una acción por violación de derechos de autor ejercitada contra esta. Mediante sus dos cuestiones prejudiciales, que el Tribunal examina conjuntamente, el órgano jurisdiccional remitente preguntaba, en esencia, si los arts. 2 a 5 de la Directiva 2001/29 deben interpretarse en el sentido de que la protección del derecho de autor que prevén se aplica a un producto cuya forma es, al menos en parte, necesaria para la obtención de un resultado técnico.

El Tribunal subraya que no cumplen el criterio de la originalidad los componentes de un objeto que se caracterizan únicamente por su función técnica, ya que del art. 2 del Tratado de la OMPI sobre derecho de autor se desprende en particular que la protección del derecho de autor no abarca las ideas. Proteger estas con el derecho de autor supondría ofrecer la posibilidad de monopolizar las ideas, en perjuicio, entre otras cosas, del progreso técnico y del desarrollo industrial. Pues bien, cuando la expresión de los citados componentes viene impuesta por su función técnica, las diferentes maneras de poner en práctica una idea son tan limitadas que la idea y la expresión se confunden.

En consecuencia, procede examinar si la bicicleta plegable controvertida en el litigio principal puede constituir una obra que se acoja a la protección prevista por la Directiva 2001/29. Es cierto que la forma que presenta la citada bicicleta resulta necesaria para la obtención de un determinado resultado técnico, a saber, la aptitud de esa bicicleta para adoptar tres posiciones, una de las cuales le permite mantenerse en equilibrio en el suelo. No obstante, corresponde al órgano jurisdiccional remitente averiguar si, a pesar de esa circunstancia, esa bicicleta constituye una obra original resultante de una creación intelectual.

A este respecto, no sucede así cuando la realización de un objeto ha venido determinada por consideraciones técnicas, reglas $\mathrm{u}$ otras exigencias que no han dejado espacio al ejercicio de la libertad creativa o han dejado un espacio tan limitado que la idea y su expresión se confunden. Aunque exista una posibilidad de decisión en cuanto a la forma de un objeto, no puede llegarse a la conclusión de que este se encuentre comprendido necesariamente en el concepto de «obra» en el sentido de la Directiva 2001/29. En el supuesto en que la forma del producto venga únicamente dictada por su función técnica, el citado producto no podrá acogerse a la protección que otorga el derecho de autor. En consecuencia, para comprobar si el producto de que se trata puede acogerse a la protección del derecho de autor, corresponde al órgano jurisdiccional remitente determinar si, por medio de la elección de la forma del producto, su autor ha expresado su capacidad creativa de manera 
original tomando decisiones libres y creativas y ha configurado el producto de modo que este refleje su personalidad.

El hecho de que en Eslovaquia la facultad de nombrar y destituir al presidente de la autoridad reguladora nacional haya sido transferida del presidente de la República al Gobierno no constituye en sí mismo una infracción de la directiva sobre el mercado de la electricidad; y, siempre que se respete la independencia de la autoridad reguladora, Eslovaquia puede establecer la participación de representantes de sus ministerios en determinados procedimientos ante dicha autoridad a efectos de garantizar la protección del interés público (Sentencia de 11 de junio de 2020, Prezident Slovenskej republiky, C-378/19, EU:C:2020:462).

En octubre de 2017, el presidente de Eslovaquia interpuso ante el Ústavný súd Slovenskej republiky (Tribunal Constitucional, Eslovaquia) un recurso con objeto de que se declarara que determinadas disposiciones nacionales relativas a la Úrad pre reguláciu siet’ových odvetví (Autoridad reguladora del sistema de redes, Eslovaquia), «autoridad reguladora nacional» de conformidad con la Directiva 2009/72/CE del Parlamento Europeo y del Consejo, sobre normas comunes para el mercado interior de la electricidad no eran compatibles con la Constitución eslovaca, en relación con el derecho de la Unión.

La actual presidenta de Eslovaquia, que prosiguió el procedimiento incoado por su predecesor, consideraba que el legislador eslovaco había incurrido en una doble injerencia en la independencia, garantizada por la directiva, de la autoridad reguladora eslovaca. La primera injerencia consistía en haber transferido la facultad de nombramiento y destitución del presidente de la autoridad reguladora del presidente de la República, directamente elegido por los ciudadanos, al Gobierno, y la segunda, en haber incluido entre las partes del procedimiento de fijación de los precios ante la autoridad reguladora a representantes de ministerios nacionales, a quienes se encomienda la defensa del interés público en el marco de dicho procedimiento.

En su sentencia, el Tribunal de Justicia hace constar que la directiva sobre el mercado de la electricidad impone a los Estados miembros la obligación de garantizar, estableciendo requisitos relativos a la independencia del personal y de los encargados de gestionar la autoridad reguladora nacional, que esta ejerza sus funciones de regulación libre de toda influencia exterior. No obstante, el Tribunal de Justicia señala que la directiva no precisa qué autoridad o autoridades de los Estados miembros son competentes para nombrar o destituir a los miembros del consejo o a los altos cargos directivos de la autoridad reguladora nacional, en particular, a su presidente. 
En consecuencia, habida cuenta del amplio margen de apreciación del que disponen los Estados miembros respecto a la elección de los medios destinados a garantizar la aplicación de las directivas adoptadas por la Unión, la directiva sobre el mercado de la electricidad no prohíbe que el Gobierno de un Estado miembro nombre y destituya al presidente de la autoridad reguladora nacional, siempre que la independencia de esta quede debidamente garantizada, extremo que compete apreciar de conformidad con el derecho eslovaco al Ústavný súd Slovenskej republiky.

En cuanto a la segunda injerencia en la independencia de la autoridad reguladora nacional que se imputa al Gobierno eslovaco, el Tribunal de Justicia pone de relieve que dicha autoridad debe adoptar sus decisiones de manera autónoma, basándose únicamente en el interés público, con el fin de asegurar que se respeten los objetivos perseguidos por la directiva sobre el mercado de la electricidad, sin estar sometida a instrucciones externas de otros organismos públicos o privados.

A este respecto, el Tribunal de Justicia observa, no obstante, que la directiva sobre el mercado de la electricidad no prohíbe la participación de representantes de ministerios nacionales en determinados procedimientos relativos a la fijación de los precios, que conciernen, en particular, al acceso a la red de transporte y de distribución de electricidad y al transporte y la distribución de electricidad. Por tanto, los Estados miembros pueden adoptar normas que permitan esa participación, siempre que se siga garantizando la independencia en la toma de decisiones de la autoridad reguladora nacional, extremo que corresponde apreciar al Tribunal Constitucional.

Así pues, el hecho de que las disposiciones controvertidas establezcan la participación de representantes de ministerios nacionales en determinados procedimientos relativos a la fijación de precios no conduce necesariamente, y por esa única razón, a que la autoridad reguladora nacional no ejerza sus funciones de fijación de precios de manera independiente. La directiva sobre el mercado de la electricidad tampoco se opone a que el Gobierno de un Estado miembro pueda hacer valer ante la autoridad reguladora nacional su posición acerca de la manera en la que considera que esta podría tener en cuenta el interés público en el ámbito de sus funciones de regulación, fundamentalmente mediante la participación de representantes de sus ministerios en los procedimientos mencionados.

No obstante, esta participación y en particular las opiniones expresadas por dichos representantes en los procedimientos relativos a la fijación de precios no pueden revestir un carácter vinculante ni ser consideradas en ningún caso por la autoridad reguladora nacional como instrucciones que deba observar en el ejercicio de sus obligaciones y competencias. Asimismo, cuando en virtud de las obligaciones y las competencias de dicha autoridad, 
enunciadas en la directiva sobre el mercado de la electricidad, sus decisiones sean obligatorias y directamente aplicables, la participación de los citados representantes en los procedimientos en cuestión no puede incidir en las características de las decisiones mencionadas. En particular, las normas de participación de los representantes de ministerios nacionales no pueden exigir que las decisiones de la autoridad reguladora sean aceptadas o autorizadas por dichos representantes con carácter previo a su aplicación.

Irlanda ha incumplido las obligaciones que le incumben en virtud de lo dispuesto en la directiva por la que se establecen los principios fundamentales que rigen la investigación de accidentes en el sector del transporte marítimo, al no haber creado un organismo de investigación independiente en su organización y toma de decisiones respecto de terceros cuyos intereses pudieran entrar en conflicto con el cometido que se le haya encomendado (Sentencia de 9 de julio de 2020, Comisión/ Irlanda, C-257/19, EU:C:2020:541).

Abundando en las exigencias de independencia de determinadas autoridades administrativas, esta sentencia condena a Irlanda en el ámbito del transporte marítimo. El art. 8, apdo 1, de la Directiva 2009/18/CE del Parlamento Europeo y del Consejo, por la que se establecen los principios fundamentales que rigen la investigación de accidentes en el sector del transporte marítimo, dispone que los Estados miembros garantizarán que las investigaciones de seguridad se lleven a cabo bajo la responsabilidad de un organismo de investigación permanente e imparcial. Dicho precepto establece asimismo que "para llevar a cabo la investigación de seguridad de una manera imparcial, el órgano de investigación será independiente en su organización, estructura jurídica y toma de decisiones respecto de terceros cuyos intereses pudieran entrar en conflicto con el cometido que se le haya encomendado».

Por lo que respecta, en primer lugar, a la cuestión de si el Department of Transports, Tourism and Sports (Ministerio de Transportes, Turismo y Deporte; DTTS en adelante), y la Oficina de Inspección de la Navegación son, a efectos del art. 8, apdo. 1, de la Directiva 2009/18, terceros cuyos intereses pudieran entrar en conflicto con el cometido que se haya encomendado al Marine Casualty Investigation Board (Oficina de Investigación sobre siniestros marítimos; $\mathrm{MCIB}$ en adelante), concluye que el MCIB, en las investigaciones que instruye, puede verse en la situación de conocer sobre las actividades realizadas directamente por el DTTS, pero también por el servicio de política de seguridad marítima, así como por los guardacostas y la Oficina de Inspección de la Navegación, del mismo modo en que, al elaborar sus informes, es posible que tenga que cuestionar la gestión de las competencias atribuidas a 
las mencionadas autoridades públicas y formular recomendaciones sobre las prácticas que deben observarse en el futuro o las reformas que han de introducirse. Por lo tanto, debe concluirse que el DTTS y la Oficina de Inspección de la Navegación son terceros cuyos intereses pueden entrar en conflicto con el cometido encomendado al MCIB, a efectos del art. 8, apdo. 1, de la Directiva 2009/18.

En segundo lugar, el Tribunal examina si, como afirmaba la Comisión, la independencia del MCIB respecto al DTTS y a la Oficina de Inspección de la Navegación no queda garantizada debido a la presencia en el seno del MCIB de dos miembros que ejercen simultáneamente funciones en el DTTS y en la Oficina de Inspección de la Navegación, respectivamente. El Tribunal señala que, puesto que la Comisión no alega que el MCIB carezca de independencia por lo que se refiere a su estructura jurídica, únicamente procede examinar si la presencia en dicho organismo del Secretario General del DTTS (o de su delegado) y del Inspector Jefe de la Oficina de Inspección de la Navegación le priva de independencia en su organización y toma de decisiones.

En cuanto al concepto de «independencia», el Tribunal de Justicia observa que ni el art. 8, apartado 1, de la Directiva 2009/18, ni ningún otro precepto de la misma directiva definen tal concepto. Por lo tanto, procede tener en cuenta su sentido habitual. Así, en lo que se refiere a los órganos públicos, la independencia designa normalmente un estatuto que asegure al órgano de que se trate la posibilidad de actuar con total libertad con respecto a los organismos frente a los cuales debe garantizarse su independencia, al abrigo de cualquier instrucción o presión.

En el caso de autos, es verdad que el art. 8 de la Ley de la Marina Mercante establece que el MCIB es independiente del DTTS en el ejercicio de sus funciones y que, con carácter general, es independiente de cualquier otra persona o institución cuyos intereses puedan ser incompatibles con el cometido desempeñado por el propio MCIB. Por otra parte, el art. 17 de la misma ley establece las normas sobre conflictos de intereses de los miembros del MCIB, el cual, por lo demás, debe atenerse a reglas deontológicas. No es menos cierto, sin embargo, que, a pesar de que dichos artículos imponen un principio general de independencia y establecen normas sobre conflictos de intereses, el art. 9, apdo. 1, de la propia Ley de la Marina Mercante, en relación con el art. 2 de la misma ley, dispone que el secretario general del DTTS y el inspector jefe de la Oficina de Inspección de la Navegación son miembros del MCIB. Pues bien, la presencia en ese organismo de investigación de dos funcionarios responsables, respectivamente, del DTTS y de la mencionada Oficina de Inspección de la Navegación, que son autoridades públicas cuyos intereses podrían entrar en conflicto con el cometido encomendado al MCIB, impide que se garantice la independencia de dicho organismo de investigación 
tanto en su organización como en su toma de decisiones. En efecto, la mera presencia de los miembros de que se trata — cuya situación de conflicto de intereses es obvia, toda vez que son al mismo tiempo miembros del MCIB y responsables de autoridades públicas cuya actuación puede ser examinada por ese organismo de investigación y ser objeto de críticas y recomendaciones por su parte- es en sí misma incompatible con la independencia de dicho organismo desde el punto de vista de su organización.

En cuanto a la influencia que los miembros de que se trata pueden ejercer sobre las decisiones del organismo de investigación, en favor, posiblemente, de los intereses de las Administraciones cuya responsabilidad ostentan, defendiendo por ejemplo las normas, procedimientos o prácticas existentes en tales Administraciones, esa influencia puede menoscabar la independencia del MCIB desde el punto de vista de la toma de decisiones. La existencia de ese conflicto de intereses y de esa posible influencia es suficiente para demostrar la infracción del art. 8, apdo. 1, de la Directiva 2009/18, ya que los Estados miembros tienen la obligación de adoptar las medidas que garanticen de antemano la independencia objetiva del organismo de investigación, como así lo confirma el uso del subjuntivo en el inciso "pudieran entrar en conflicto», que figura en esa misma disposición.

Por consiguiente, contrariamente a lo alegado por Irlanda, para acreditar la infracción no es preciso comprobar que el organismo de investigación haya actuado en casos concretos con parcialidad, ya que los requisitos de independencia deben concurrir de manera objetiva, de tal modo que el MCIB quede al abrigo de cualquier influencia ejercida, directa o indirectamente, por terceros cuyos intereses puedan entrar en conflicto con el cometido que se le haya encomendado.

Una normativa nacional puede establecer un plazo de prescripción de la acción de restitución ejercitada sobre la base de una cláusula abusiva incluida en un contrato celebrado entre un profesional y un consumidor, pero ese plazo no debe ser menos favorable que el aplicable a recursos similares del derecho nacional y no debe imposibilitar en la práctica ni dificultar excesivamente el ejercicio de los derechos conferidos por el derecho de la Unión (Sentencia de 9 de julio de 2020, Raiffeisen Bank SA/JB, C-698/18, y BRD Groupe Société Générale SA/ KC, C-699/18, EU:C:2020:537).

JB y KC celebraron sendos contratos de préstamo personal con Raiffeisen Bank y con BRD Groupe Société Générale, respectivamente. Tras haber reembolsado íntegramente el importe de sus préstamos respectivos, cada uno de ellos presentó una demanda ante el Judecătoria Târgu Mureș (Tribunal de 
Primera Instancia de Târgu Mureș, Rumanía) solicitando que se declarase el carácter abusivo de determinadas cláusulas de dichos contratos que establecían el pago de comisiones de gestión y de administración mensual y la posibilidad de que el banco modificara el importe de los intereses. Raiffeisen Bank y BRD Groupe Société Générale se opusieron indicando que, en la fecha de presentación de las demandas, JB y KC ya no tenían la condición de consumidores, al haber concluido los contratos de préstamo como consecuencia de su cumplimiento íntegro y que ya no estaban legitimados para ejercitar una acción judicial.

En este contexto, el Tribunalul Specializat Mureş (Tribunal Especializado de Mureş, Rumanía) pregunta al Tribunal de Justicia si la Directiva 93/13/ CEE del Consejo, sobre las cláusulas abusivas en los contratos celebrados con consumidores, sigue aplicándose tras el cumplimiento íntegro de un contrato $\mathrm{y}$, en su caso, si una acción de restitución de las cantidades cobradas con arreglo a cláusulas contractuales consideradas abusivas puede quedar sujeta a un plazo de prescripción de tres años, que empieza a correr una vez que ha concluido el contrato.

En su sentencia, el Tribunal de Justicia recuerda, para empezar, que la obligación del juez nacional de dejar sin aplicación una cláusula contractual abusiva que imponga el pago de importes que resulten ser cantidades indebidas implica la restitución de esos importes.

No obstante, el Tribunal de Justicia señala que, a falta de normativa de la Unión en la materia, corresponde al ordenamiento jurídico interno de cada Estado miembro establecer la regulación procesal de los recursos judiciales para garantizar la salvaguarda de los derechos de los ciudadanos de la Unión. Esta regulación, sin embargo, no debe ser menos favorable que la aplicable a recursos similares de carácter interno (principio de equivalencia) y, por otra parte, no debe imposibilitar en la práctica ni dificultar excesivamente el ejercicio de los derechos conferidos por el ordenamiento jurídico de la Unión (principio de efectividad).

Por lo que se refiere al principio de efectividad, el Tribunal de Justicia recuerda que el sistema de protección establecido por la directiva sobre las cláusulas abusivas en los contratos celebrados con consumidores se basa en la idea de que el consumidor se halla en situación de inferioridad respecto al profesional. A este respecto, y por más que un plazo de prescripción de tres años parezca, en principio, materialmente suficiente para permitir que el consumidor prepare e interponga un recurso efectivo, en la medida en que empiece a correr a partir de la fecha del cumplimiento íntegro del contrato, ese plazo podría haber expirado antes incluso de que el consumidor hubiese podido tener conocimiento del carácter abusivo de una cláusula contenida 
en dicho contrato. Por lo tanto, ese plazo no garantiza al consumidor una protección efectiva.

En estas circunstancias, circunscribir exclusivamente la protección conferida al consumidor a la vigencia del contrato en cuestión no es acorde con el sistema de protección instaurado por esa directiva. El principio de efectividad se opone, por tanto, a que la acción de restitución quede sujeta a un plazo de prescripción de tres años que empieza a correr desde la fecha en que finaliza el contrato en cuestión, con independencia de si el consumidor tenía o podía razonablemente tener conocimiento, en esa fecha, del carácter abusivo de una cláusula de ese contrato.

Por lo que se refiere al principio de equivalencia, el Tribunal de Justicia recuerda que su observancia exige que la norma nacional de que se trate se aplique indistintamente a los recursos basados en la vulneración del derecho de la Unión y a los que se fundamentan en el incumplimiento del derecho interno y que tengan un objeto y una causa semejantes. A este respecto, dicho principio se opone a una interpretación de la legislación nacional que considera que el plazo de prescripción de una acción judicial de restitución de las cantidades pagadas indebidamente a consecuencia de una cláusula abusiva empieza a correr a partir de la fecha de cumplimiento íntegro del contrato, mientras que, tratándose de una acción similar de derecho interno, ese mismo plazo empieza a correr a partir de la fecha de la declaración judicial de la causa de la acción.

El Tribunal de Justicia concluye que la directiva no se opone a una normativa nacional que, al mismo tiempo que establece la imprescriptibilidad de la acción destinada a declarar la nulidad de una cláusula abusiva incluida en un contrato celebrado entre un profesional y un consumidor, somete a un plazo de prescripción la acción dirigida a hacer valer los efectos restitutorios de esa declaración. No obstante, ese plazo no debe ser menos favorable que el aplicable a recursos similares de carácter interno y no debe imposibilitar en la práctica ni dificultar excesivamente el ejercicio de los derechos conferidos por el ordenamiento jurídico de la Unión.

La mencionada directiva, así como los principios de equivalencia y de efectividad, se oponen a una interpretación jurisdiccional de la normativa nacional según la cual la acción judicial de restitución de las cantidades pagadas indebidamente con arreglo a una cláusula abusiva queda sujeta a un plazo de prescripción de tres años que empieza a correr desde la fecha de cumplimiento íntegro de ese contrato cuando se presume, sin necesidad de verificación, que en esa fecha el consumidor debería tener o debería haber tenido conocimiento del carácter abusivo de la cláusula en cuestión o cuando, para acciones similares basadas en ciertas disposiciones del derecho interno, 
ese mismo plazo únicamente empieza a correr a partir de la declaración judicial de la causa de esas acciones.

Una autorización de comercialización que se refiere a una nueva aplicación terapéutica de un principio activo, o de una combinación de principios activos, no puede considerarse la primera autorización de comercialización a los afectos del certificado complementario de protección (CCP) cuando tal autorización se refiere a un principio activo, o a una combinación de principios activos, que ya ha sido objeto de una autorización de comercialización para otra aplicación terapéutica (Sentencia de 9 de julio de 2020, Santen, C-673/18, EU:C:2020:531).

Santen, laboratorio farmacéutico especializado en oftalmología, es titular de una patente europea, registrada el 10 de octubre de 2005, que protege una emulsión oftálmica cuyo principio activo es la ciclosporina, un agente inmunosupresor. Dicho laboratorio obtuvo igualmente, el 19 de marzo de 2015, una autorización de comercialización expedida por la Agencia Europea de Medicamentos (EMA) para el medicamento comercializado con el nombre de Ikervis, cuyo principio activo también es la ciclosporina.

Amparándose en la patente de base en cuestión y en esta autorización de comercialización, Santen presentó, el 3 de junio de 2015, una solicitud de certificado complementario de protección (CCP) para un producto denominado Ciclosporina para el tratamiento de la queratitis. Mediante decisión de 6 de octubre de 2017, el director general del Instituto Nacional de la Propiedad Industrial (INPI) denegó la solicitud de CCP al considerar que la citada autorización de comercialización no constituía la primera autorización de comercialización que se presentaba para la ciclosporina.

Mediante su sentencia, el Tribunal de Justicia, en formación de Gran Sala, se pronunció sobre si es posible considerar que una autorización de comercialización es la primera autorización de comercialización de un producto como medicamento, en el sentido del art. 3, letra d), del Reglamento (CE) 469/2009 del Parlamento Europeo y del Consejo, relativo al certificado complementario de protección para los medicamentos, cuando tal autorización se refiere a una nueva aplicación terapéutica de un principio activo, o de una combinación de principios activos, que ya ha sido objeto de una autorización de comercialización para otra aplicación terapéutica.

En primer lugar, el Tribunal de Justicia procedió a examinar la cuestión de si el concepto de "producto", según dispone el art. 1, letra b), del Reglamento 469/2009, depende de la aplicación terapéutica del principio activo. A este respecto, el Tribunal de Justicia destacó que, a efectos de la aplicación del reglamento relativo al CCP para los medicamentos, este concepto se refiere 
al principio activo o a la composición de principios activos de un medicamento. Asimismo, precisó que, al no figurar definición alguna del concepto de "principio activo» en dicho reglamento, el alcance de ese concepto no debe limitarse a una sola de las aplicaciones terapéuticas a las que tal principio activo, o tal combinación de principios activos, puede dar lugar. En efecto, el Tribunal de Justicia subrayó que, aunque la protección conferida al producto por el CCP se extienda únicamente al producto amparado por la autorización de comercialización, se aplica a cualquier utilización del producto como medicamento que haya sido autorizada antes de la expiración del CCP (art. 4 del Reglamento 469/2009). En estas condiciones, el Tribunal de Justicia concluyó que el hecho de que un principio activo, o una combinación de principios activos, se utilice para una nueva aplicación terapéutica no le confiere la cualidad de producto distinto cuando el mismo principio activo, o la misma combinación de principios activos, haya sido utilizado para otra aplicación terapéutica ya conocida.

En segundo lugar, el Tribunal de Justicia precisó el concepto de «primera autorización de comercialización del producto como medicamento" a que hace referencia el art. 3, letra d), del reglamento relativo al CCP para los medicamentos. Así, puntualizó que para definir este concepto no debe tenerse en cuenta el ámbito de protección de la patente de base. En efecto, al instituir el régimen del CCP, la voluntad del legislador de la Unión ha sido fomentar la protección de la investigación farmacéutica que conduce a la primera comercialización de un principio activo o de una combinación de principios activos como medicamento y no cualquier investigación farmacéutica que dé lugar a la concesión de una patente y a la comercialización de un nuevo medicamento. De este modo, el Tribunal de Justicia concluyó que, a efectos del art. 3 , letra d), no es posible considerar que una autorización de comercialización sea la primera autorización de comercialización cuando tal autorización se refiere a una nueva aplicación terapéutica de un principio activo, o de una combinación de principios activos, que ya ha sido objeto de una autorización de comercialización para otra aplicación terapéutica.

\section{MEDIO AMBIENTE}

Una orden y una circular que establecen las condiciones generales para la concesión de autorizaciones urbanísticas para la instalación y explotación de aerogeneradores también deben ser objeto de una evaluación medioambiental previa (Sentencia de 25 de junio de 2020, Gewestelijke stedenbouwkundige ambtenaar van het departement Ruimte Vlaanderen, afdeling Oost-Vlaanderen, C-24/19, EU:C:2020:503). 
El Tribunal de Justicia, constituido en Gran Sala, se pronunció en este asunto sobre la interpretación de la Directiva 2001/42/CE del Parlamento Europeo y del Consejo, relativa a la evaluación de los efectos de determinados planes y programas en el medio ambiente, aportando importantes precisiones sobre las medidas sometidas a la evaluación establecida en dicha directiva y sobre las consecuencias resultantes de una omisión de evaluación.

Esta petición de interpretación se planteó en el marco de un litigio entre unos residentes en un emplazamiento cercano a la autopista E40, en el término municipal de Aalter y de Nevele, previsto para acoger un parque eólico y el Gewestelijke stedenbouwkundige ambtenaar van het departement Ruimte Vlaanderen, afdeling Oost-Vlaanderen (Funcionario Regional de Urbanismo del Departamento de Ordenación del Territorio de Flandes - Sección Flandes Oriental, Bélgica), en relación con la concesión por esta autoridad de una autorización urbanística para la instalación y explotación de cinco aerogeneradores. La concesión de la autorización controvertida se había supeditado, en concreto, al cumplimiento de determinados requisitos establecidos en unas disposiciones de una orden del Gobierno flamenco y en una circular referente a la instalación y explotación de aerogeneradores. En apoyo del recurso dirigido a la anulación de la autorización controvertida interpuesto ante el Raad voor Vergunningsbetwistingen (Consejo del Contencioso de Autorizaciones, Bélgica), los demandantes invocaban, en particular, la infracción de la Directiva 2001/42 debido a que la orden y la circular en las que se había basado la concesión de la autorización no habían sido objeto de una evaluación medioambiental.

En su sentencia, el Tribunal de Justicia recordó que la Directiva 2001/42 comprende los planes y programas, así como sus modificaciones, elaborados o adoptados por una autoridad de un Estado miembro, siempre que hayan sido «exigidos por disposiciones legales, reglamentarias o administrativas». Además, su art. 3, apdo. 1, supedita la obligación de someter un plan o un programa concreto a una evaluación medioambiental al requisito de que el plan o el programa pueda tener efectos significativos en el medio ambiente.

En primer lugar, por lo que se refiere al concepto de "planes y programas que sean exigidos por disposiciones legales, reglamentarias o administrativas", el Tribunal de Justicia declaró que están comprendidas en este concepto una orden y una circular, adoptadas por el Gobierno de una entidad federada de un Estado miembro, que contienen diversas disposiciones relativas a la instalación y explotación de aerogeneradores. En efecto, de reiterada jurisprudencia del Tribunal de Justicia se desprende que deben considerarse «exigidos», a efectos de la referida directiva y para su aplicación, los planes y programas cuya adopción esté regulada en disposiciones legales o reglamentarias nacionales, las cuales determinarán qué autoridades son competentes para adoptarlos y 
su procedimiento de elaboración. Así pues, una medida debe considerarse «exigida» cuando la base jurídica de la facultad para adoptarla se encuentre en una disposición de esa naturaleza, incluso si no existe ninguna obligación, propiamente dicha, de adoptar tal medida.

Instado por el tribunal remitente y el Gobierno del Reino Unido a reconsiderar dicha jurisprudencia, el Tribunal de Justicia subrayó, en primer término, que limitar el requisito contemplado en el art. 2, letra a), segundo guion, de la Directiva 2001/42 únicamente a los «planes y programas» de adopción obligatoria podía conferirle un alcance marginal y no permitiría preservar la eficacia de esa disposición. Según el Tribunal de Justicia, dada la diversidad de situaciones y la heterogeneidad de las prácticas de las autoridades nacionales, la adopción de planes o programas y sus modificaciones no se impone a menudo de manera general ni se deja a la entera discreción de las autoridades competentes. Además, el nivel elevado de protección del medio ambiente que pretende garantizar la Directiva 2001/42 sometiendo a evaluación medioambiental los planes y programas que puedan tener efectos significativos en el medio ambiente responde a las exigencias del art. 3 TUE, apdo. 3; del art. 191 TFUE, apdo. 2, y del art. 37 de la Carta de los Derechos Fundamentales en materia de protección y de mejora de la calidad del medio ambiente. Pues bien, tales objetivos podrían verse comprometidos por una interpretación restrictiva, que permitiera a un Estado miembro eludir la obligación de evaluación medioambiental al evitar hacer obligatoria la adopción de los planes o programas. Finalmente, el Tribunal de Justicia destacó que la interpretación amplia del concepto de "planes y programas» era conforme con los compromisos internacionales de la Unión, tal como resultan, en particular, del art. 2, apdo. 7, del Convenio sobre la Evaluación del Impacto Ambiental en un Contexto Transfronterizo, firmado en Espoo (Finlandia) el 26 de febrero de 1991.

El Tribunal de Justicia examinó, en segundo término, si la orden y la circular de que se trata cumplían el requisito contemplado en el art. 2, letra a), segundo guion, de la Directiva 2001/42. A este respecto, señaló que la orden había sido adoptada por el Gobierno flamenco, como poder ejecutivo de una entidad federada belga, en virtud de una habilitación legislativa. Además, la circular, cuya finalidad es regular la facultad de apreciación de las autoridades competentes, procede también del Gobierno flamenco y modifica las disposiciones de dicha orden, desarrollándolas o estableciendo excepciones a ellas, sin perjuicio de las comprobaciones que corresponde efectuar al tribunal nacional en cuanto a su naturaleza jurídica exacta y a su contenido preciso. Por lo tanto, el Tribunal de Justicia concluyó que la orden y, sin perjuicio de tales comprobaciones, la circular estaban comprendidas en el concepto de «planes y 
programas», en la medida en que debían considerarse «exigidas», en el sentido de la Directiva 2001/42.

En segundo lugar, por lo que respecta a si la orden y la circular debían someterse a una evaluación medioambiental con arreglo a la Directiva 2001/42, debido a que podrían tener efectos significativos en el medio ambiente, el Tribunal de Justicia declaró que esos actos, que contenían diversas disposiciones relativas a la instalación y explotación de aerogeneradores, entre ellas, medidas relativas a la proyección de sombra, a la seguridad y a las normas sobre ruidos, se encontraban entre los que debían ser objeto de tal evaluación.

Sobre este particular, el Tribunal de Justicia consideró que las prescripciones establecidas en la orden y en la circular de que se trata, en relación con la instalación y explotación de aerogeneradores, revestían una importancia y un alcance lo suficientemente significativos como para determinar los requisitos a los que se supeditaba la concesión de una autorización para la instalación y explotación de parques eólicos, cuyo impacto medioambiental es innegable. Precisó que tal interpretación no quedaba desvirtuada por la naturaleza jurídica particular de la circular.

En tercer y último lugar, por lo que se refiere a la posibilidad de mantener los efectos de esos actos y de la autorización, adoptados infringiendo la Directiva 2001/42, el Tribunal de Justicia recordó que los Estados miembros están obligados a eliminar las consecuencias ilícitas de tal violación del derecho de la Unión. Subrayó que, habida cuenta de la exigencia de la aplicación uniforme del derecho de la Unión, solo podía, con carácter excepcional y en atención a consideraciones imperiosas de interés general, conceder la suspensión provisional del efecto de exclusión vinculado a la disposición del derecho de la Unión infringida, siempre que una normativa nacional facultase al tribunal nacional para mantener determinados efectos de tales actos en el marco del litigio del que conoce. En consecuencia, el Tribunal de Justicia declaró que, en una situación como la del presente caso, el tribunal nacional solo podía mantener los efectos de la orden y de la circular, así como de la autorización concedida basándose en ellas, si se lo permitía el derecho interno en el marco del litigio del que conocía, en el supuesto de que la anulación de la referida autorización pudiera tener repercusiones significativas en el suministro de electricidad —en el caso de autos, en Bélgica - y únicamente durante el tiempo estrictamente necesario para corregir dicha ilegalidad, extremo que corresponde apreciar, en su caso, al tribunal nacional.

Cuando los vicios procedimentales no puedan modificar las decisiones de autorización de proyectos, el legislador nacional tendrá la posibilidad de supeditar la admisibilidad de los recursos de anulación por vicio procedimental de dichas decisiones a que ese vicio haya privado 
en realidad a los demandantes de su derecho a participar en la toma de decisiones, pero los miembros del público interesado por cada proyecto deben poder invocar ante los tribunales nacionales competentes el incumplimiento de las obligaciones de evitar el deterioro y mejorar el estado de las masas de agua cuando se vean directamente afectados por dicho incumplimiento (Sentencia de 28 de mayo de 2020, IL y otros contra Land Nordrhein-Westfalen, C-535/18, EU:C:2020:391).

La petición de decisión prejudicial versaba sobre la interpretación de los arts. 6 y 11, apdo. 1, letra b), de la Directiva 2011/92/UE del Parlamento Europeo y del Consejo, relativa a la evaluación de las repercusiones de determinados proyectos públicos y privados sobre el medio ambiente, y del art. 4, apdo. 1, letras a), incisos i) a iii), y b), inciso i), de la Directiva 2000/60/CE del Parlamento Europeo y del Consejo, por la que se establece un marco comunitario de actuación en el ámbito de la política de aguas. Esta petición se había presentado en el contexto de un litigio seguido entre distintos particulares y el Land Nordrhein-Westfalen (Land de Renania del Norte-Westfalia, Alemania) en relación con la decisión de las autoridades de la Bezirksregierung Detmold (autoridad administrativa del Distrito de Detmold, Alemania) por la que se aprobó el plan de construcción de un enlace de autopista de unos 3,7 kilómetros.

Mediante su primera cuestión prejudicial el tribunal remitente deseaba averiguar si el art. 11, apdo. 1, letra b), de la Directiva 2011/92 debe interpretarse en el sentido de que permite que los Estados miembros establezcan que las solicitudes de anulación por vicios procedimentales de decisiones de autorización de proyectos solo sean admisibles si las irregularidades en cuestión privaron a los demandantes del derecho que les garantiza el art. 6 de dicha directiva a la participación en la toma de decisiones medioambientales.

El Tribunal recuerda que, según el art. 11, apdo. 1, de la Directiva 2011/92, los Estados miembros garantizarán que, de conformidad con su derecho interno, los miembros del "público interesado», ya sea que tengan un interés suficiente, ya sea que sostengan que se ha producido el menoscabo de un derecho, cuando la legislación en materia de procedimiento administrativo de un Estado miembro lo imponga como requisito previo, tengan la posibilidad de presentar un recurso contra las decisiones, acciones y omisiones que caigan dentro del ámbito de las disposiciones de dicha directiva para impugnar su legalidad, en cuanto al fondo o en cuanto al procedimiento. En ese sentido, la admisibilidad de un recurso puede supeditarse al «interés suficiente» o a la existencia de un "menoscabo a un derecho», dependiendo de cuál de estos dos requisitos exija la legislación nacional. El art. 11, apdo. 3, de la Directiva 2011/92 prevé que los Estados miembros determinen, de manera coherente 
con el objetivo de facilitar al público interesado un amplio acceso a la justicia, lo que constituya el interés suficiente y el menoscabo de un derecho.

Sobre ese particular, el Tribunal de Justicia ya había declarado que el legislador nacional tiene la posibilidad de establecer que los derechos subjetivos (es decir, los derechos individuales que según el derecho nacional pueden calificarse de derechos subjetivos públicos) sean los únicos derechos cuya vulneración puede ser invocada por un particular para interponer un recurso judicial contra las decisiones, acciones u omisiones contemplados en el art. 10 bis de la Directiva 85/337/CEE del Consejo, relativa a la evaluación de las repercusiones de determinados proyectos públicos y privados sobre el medio ambiente, actualmente art. 11 de la Directiva 2011/92. El Tribunal de Justicia ha declarado asimismo que, cuando un vicio procedimental no entraña consecuencias que puedan afectar al sentido de la decisión impugnada, no es posible considerar que el vicio menoscabe los derechos de quien lo invoca. Así pues, tomando en consideración que el art. 11 de la Directiva 2011/92 concede a los Estados miembros un margen de maniobra apreciable para determinar qué constituye menoscabo de un derecho a los efectos del apdo. 1, letra b), de dicho art., el derecho nacional puede no reconocer ese menoscabo si se acredita que, habida cuenta de las circunstancias del caso, probablemente la decisión impugnada no habría sido distinta sin el vicio procedimental invocado. Por consiguiente, cuando los vicios procedimentales no puedan modificar las decisiones de autorización de proyectos, el legislador nacional tendrá la posibilidad de supeditar la admisibilidad de los recursos de anulación por vicio procedimental de dichas decisiones a que ese vicio haya privado en realidad a los demandantes de su derecho a participar en la toma de decisiones.

El tribunal remitente deseaba también averiguar si, a la luz del art. 19TUE y el art. 288 TFUE, el art. 4, apdo. 1, de la Directiva 2000/60 debe interpretarse en el sentido de que los miembros del público interesado por cada proyecto deben poder invocar ante los tribunales nacionales competentes el incumplimiento de las obligaciones de evitar el deterioro y mejorar el estado de las masas de agua.

A ese respecto, el Tribunal de Justicia recuerda que, según su reiterada jurisprudencia, sería incompatible con el carácter imperativo que el art. 288 TFUE reconoce a las directivas excluir a priori que las personas afectadas puedan invocar las obligaciones que dichas directivas imponen. En especial, en los casos en los que el legislador de la Unión obliga a los Estados miembros a través de una directiva a adoptar un determinado comportamiento, la eficacia de tal acto quedaría debilitada si se impidiera a los justiciables invocarlo ante los tribunales y si los órganos jurisdiccionales nacionales no pudieran tomarlo en consideración, como elemento del derecho de la Unión, para verificar si el legislador nacional, dentro de los límites de la facultad de que dispone en 
cuanto a la forma y los medios de ejecutar la directiva, ha sobrepasado o no los límites del margen de apreciación trazado por ella. De ello el Tribunal de Justicia ha deducido que al menos las personas físicas o jurídicas directamente afectadas por el incumplimiento de las disposiciones de una directiva medioambiental deben disponer de la facultad de exigir a las autoridades competentes, en su caso por vía judicial, el cumplimiento de las obligaciones de que se trate.

Con objeto de determinar si unas personas tales como los demandantes en el litigio principal resultan directamente afectadas por el incumplimiento de las obligaciones establecidas por el art. 4, apdo. 1, letra b), de la Directiva 2000/60, procede tener en cuenta la finalidad de esta y la literalidad de la disposición pertinente de dicha Directiva cuya correcta aplicación se reclama ante el tribunal remitente. El Tribunal concluye que la Directiva 2000/60, por su finalidad y por las obligaciones que para lograrla establece su art. 4, apdo. 1 , letra b), persigue asimismo el objetivo concreto de proteger el agua subterránea como recurso para la explotación por el ser humano. Por ello concluye que, a la luz del art. 19 TUE y el art. 288 TFUE, los arts. 1, letra b) y primer guion, y 4, apdo. 1, letra b), de la Directiva 2000/60 deben interpretarse en el sentido de que los miembros del público interesado por cada proyecto deben poder invocar ante los tribunales nacionales competentes el incumplimiento de las obligaciones de evitar el deterioro y mejorar el estado de las masas de agua cuando se vean directamente afectados por dicho incumplimiento.

\section{JUSTICIA, LIBERTAD Y SEGURIDAD}

El ingreso de los solicitantes de asilo o de los nacionales de terceros países objeto de una decisión de retorno en la zona de tránsito de Röszke, en la frontera serbo-húngara, debe calificarse de «internamiento» y si, tras efectuarse el control judicial de la regularidad de ese internamiento, queda acreditado que las personas en cuestión han sido internadas sin un motivo válido, el órgano jurisdiccional que conoce del asunto debe ponerlas en libertad de manera inmediata (sentencia de 14 de mayo de 2020, Országos Idegenrendészeti Főigazgatóság Dél-alföldi Regionális Igazgatóság (C-924/19 PPU y C-925/19 PPU, EU:C:2020:367)

En esta sentencia, la Gran Sala del Tribunal de Justicia se pronunció sobre numerosas cuestiones relativas a la interpretación de las Directiva 2008/115/ CE del Parlamento Europeo y del Consejo, relativa a normas y procedimientos comunes en los Estados miembros para el retorno de los nacionales de terceros países en situación irregular ("Directiva "Retorno”»), 2013/32/UE 
del Parlamento Europeo y del Consejo, sobre procedimientos comunes para la concesión o la retirada de la protección internacional («Directiva "Procedimientos"») y 2013/33/UE del Parlamento Europeo y del Consejo, por la que se aprueban normas para la acogida de los solicitantes de protección internacional («Directiva "Acogida”), en relación con la normativa húngara reguladora del derecho de asilo y del retorno de los nacionales de países terceros en situación irregular.

En el caso de autos, unos nacionales afganos (asunto C-924/19 PPU) e iraníes (asunto C-925/19 PPU) que habían llegado a Hungría a través de Serbia presentaron sendas solicitudes de asilo en la zona de tránsito de Röszke, situada en la frontera serbohúngara. Con arreglo al derecho húngaro, estas solicitudes se desestimaron por inadmisibles y se dictaron sendas decisiones de retorno hacia Serbia. Sin embargo, Serbia rehusó readmitir a los interesados en su territorio por cuanto no se cumplían los requisitos establecidos por el Acuerdo entre la Comunidad Europea y la República de Serbia sobre la readmisión de residentes ilegales. Tras esta decisión de Serbia, las autoridades húngaras no procedieron a efectuar un examen del fondo de las citadas solicitudes, sino que modificaron el país de destino indicado en las decisiones de retorno iniciales, sustituyéndolo por los respectivos países de origen de los interesados. A continuación, estos formularon impugnación contra las referidas decisiones modificativas, impugnación que fue desestimada. Aunque en el derecho húngaro no se prevé esta posibilidad, los interesados interpusieron recurso ante un órgano jurisdiccional húngaro con la pretensión de que se anulasen las resoluciones por las que se habían desestimado sus impugnaciones de las referidas decisiones modificativas y de que se conminase a la autoridad competente en materia de asilo para que tramitase un nuevo procedimiento de asilo. Presentaron asimismo sendos recursos por omisión en relación con su ingreso y mantenimiento en la zona de tránsito de Röszke. En efecto, primero se los obligó a permanecer en el sector de dicha zona de tránsito reservado a los solicitantes de asilo, y después, unos meses más tarde, se los obligó a permanecer en el sector de dicha zona reservado a los nacionales de países terceros cuya solicitud de asilo ha sido desestimada, en el cual se encuentran actualmente.

En primer lugar, el Tribunal de Justicia examinó la situación de los interesados en la zona de tránsito de Röszke, a la luz de las normas que regulan tanto el internamiento de los solicitantes de protección internacional (directivas «Procedimientos» $\mathrm{y}$ «Acogida») como el de los nacionales de terceros países en situación irregular (Directiva «Retorno»). A este respecto, el Tribunal de Justicia declaró, para empezar, que el ingreso de los interesados en la referida zona de tránsito debía ser considerada una medida de internamiento. Para llegar a esta conclusión precisó que el concepto de «internamiento», que tiene 
el mismo significado en el contexto de las distintas directivas citadas, se refiere a una medida coercitiva que entraña una privación, y no una mera restricción, de la libertad de circulación del interesado y lo aísla del resto de la población, obligándolo a permanecer sin solución de continuidad en un perímetro restringido y cerrado. Pues bien, según el Tribunal de Justicia, las condiciones imperantes en la zona de tránsito de Röszke se asemejan a una privación de libertad, en particular porque los interesados no pueden, legalmente, abandonarla de manera voluntaria en ninguna dirección. Concretamente, no pueden abandonarla en dirección a Serbia por cuanto tal tentativa, por un lado, sería considerada ilegal por las autoridades serbias y, por tal motivo, los expondría a sanciones y, por otro lado, podría suponer que perdiesen la posibilidad de obtener el estatuto de refugiado en Hungría.

A continuación, el Tribunal de Justicia examinó la conformidad de este internamiento con las exigencias que impone el derecho de la Unión. Por lo que se refiere a las exigencias vinculadas al internamiento, el Tribunal de Justicia declaró que, en virtud, respectivamente, del art. 8 de la directiva «Acogida» y del art. 15 de la directiva «Retorno», ni un solicitante de protección internacional ni un nacional de un tercer país sobre el que pese una decisión de retorno pueden ser internados solo porque no puedan satisfacer sus necesidades. El Tribunal de Justicia añadió que los arts. 8 y 9 de la directiva «Acogida» y el art. 15 de la directiva "Retorno» se oponen, respectivamente, a que se interne a un solicitante de protección internacional o a un nacional de un tercer país sobre el que pese una decisión de retorno sin que antes se haya adoptado una resolución motivada que ordene el internamiento y se hayan examinado la necesidad y la proporcionalidad de tal medida.

El Tribunal de Justicia también aportó precisiones con respecto a las exigencias vinculadas al mantenimiento del internamiento y, más concretamente, a su duración. Por lo que se refiere a los solicitantes de protección internacional, declaró que el art. 9 de la directiva "Acogida» no obliga a que los Estados miembros fijen una duración máxima del mantenimiento del internamiento. No obstante, su derecho nacional debe garantizar que el internamiento solo dure mientras siga siendo de aplicación el motivo que lo justifique y se ejecuten con diligencia los procedimientos administrativos relacionados con ese motivo. En cambio, por lo que respecta a los nacionales de terceros países sobre los que pesa una decisión de retorno, del art. 15 de la directiva "Retorno" se desprende que su internamiento, incluso cuando se prorrogue, no puede exceder de dieciocho meses y que solo puede mantenerse mientras estén en curso y se ejecuten con la debida diligencia los trámites de expulsión.

Por otra parte, en lo que se refiere al internamiento de los solicitantes de protección internacional en el contexto particular de una zona de tránsito, 
también resulta necesario tener en cuenta el art. 43 de la directiva «Procedimientos». De esta disposición resulta que los Estados miembros pueden obligar a los solicitantes de protección internacional a permanecer en sus fronteras o en alguna de sus zonas de tránsito, en particular, para examinar, antes de decidir sobre el derecho de entrada a su territorio de estos solicitantes, si su solicitud no es inadmisible. No obstante, debe adoptarse una decisión en el plazo de cuatro semanas, en defecto de lo cual el Estado miembro de que se trate debe conceder al solicitante el derecho a entrar en su territorio y tramitar su solicitud de conformidad con el procedimiento ordinario. Por lo tanto, si bien los Estados miembros pueden, en el marco del procedimiento contemplado en el referido art. 43, internar a los solicitantes de protección internacional que se presenten en sus fronteras, este internamiento no puede exceder en ningún caso de cuatro semanas a contar desde la fecha de presentación de la solicitud.

Por último, el Tribunal de Justicia declaró que la legalidad de una medida de internamiento como aquella a la que se sujeta a una persona en una zona de tránsito debe poder ser objeto de control judicial, en virtud, respectivamente, del art. 9 de la directiva "Acogida» y del art. 15 de la directiva «Retorno». En consecuencia, si no existen disposiciones nacionales que prevean tal control, el principio de primacía del derecho de la Unión y el derecho a la tutela judicial efectiva obligan al órgano jurisdiccional ante el que se haya interpuesto recurso a declararse competente para resolver a este respecto. Es más, si, una vez efectuado este control, el órgano jurisdiccional nacional considera que la medida de internamiento en cuestión es contraria al derecho de la Unión, debe poder sustituir la decisión de la autoridad administrativa que la ordenó por la suya propia y decretar la puesta en libertad inmediata de las personas afectadas, o eventualmente una medida alternativa al internamiento.

Por otro lado, el solicitante de protección internacional cuyo internamiento, considerado ilegal, haya finalizado debe poder pedir que se le concedan las condiciones materiales de acogida a las que tiene derecho durante el examen de su solicitud. En particular, se desprende del art. 17 de la directiva "Acogida» que, si no dispone de medios de subsistencia, tiene derecho a obtener una asignación financiera que le permita alojarse o un alojamiento en especie. A estos efectos, el art. 26 de la directiva "Acogida» obliga a que tal solicitante pueda interponer recurso ante un órgano jurisdiccional al objeto de que se le garantice dicho derecho al alojamiento, disponiendo este órgano jurisdiccional de la posibilidad de acordar medidas cautelares en espera de su decisión definitiva. Si ningún otro órgano jurisdiccional tiene competencia con arreglo al derecho nacional, el principio de primacía del derecho de la Unión y el derecho a la tutela judicial efectiva obligan, también en este caso, al órgano jurisdiccional ante el que se haya instado esta acción a 
declararse competente para conocer del recurso dirigido a que se garantice el derecho al alojamiento.

En segundo lugar, el Tribunal de Justicia se pronunció sobre la competencia del órgano jurisdiccional nacional para conocer del recurso de anulación interpuesto por los interesados contra las resoluciones por las que se habían desestimado sus impugnaciones de la modificación del país de retorno. A este respecto, el Tribunal de Justicia señaló que una decisión por la que se modifica el país de destino indicado en la decisión de retorno inicial es tan sustancial que debe ser considerada una nueva decisión de retorno. En virtud del art. 13 de la directiva "Retorno», los destinatarios de tal decisión deben disponer de una vía de recurso efectiva contra ella, la cual también debe ser conforme con el derecho a la tutela judicial efectiva garantizado por el art. 47 de la Carta de los Derechos Fundamentales de la Unión Europea. Desde esta perspectiva, el Tribunal de Justicia recordó que, si bien los Estados miembros pueden prever que las decisiones de retorno hayan de impugnarse ante autoridades que no sean jurisdiccionales, el destinatario de una decisión de retorno adoptada por una autoridad administrativa debe poder, no obstante, en algún momento del procedimiento, impugnar su regularidad ante al menos un órgano jurisdiccional. En el caso de autos, el Tribunal de Justicia señaló que los interesados solamente podían impugnar las resoluciones de la autoridad de policía de extranjería por las que se modificaba su país de retorno ante la autoridad competente en materia de asilo y que no se garantizaba ningún control judicial ulterior. Pues bien, esta última autoridad, que se encuentra sometida al ministro responsable de las fuerzas del orden, forma parte del Poder Ejecutivo, de manera que no satisface el requisito de independencia que se exige de los órganos jurisdiccionales a los efectos del art. 47 de la Carta. En tales circunstancias, el principio de primacía del derecho de la Unión, así como el derecho a la tutela judicial efectiva, obliga al órgano jurisdiccional nacional que conozca del asunto a declararse competente para resolver el recurso dirigido a impugnar una decisión de retorno por la que se modifica el país de destino inicial, dejando inaplicada, si fuera necesario, cualquier disposición nacional que se lo prohíba.

En tercer lugar, el Tribunal de Justicia examinó el motivo de inadmisibilidad recogido en la normativa húngara que justificó la desestimación de las solicitudes de asilo. Esta normativa permite tal desestimación cuando el solicitante haya llegado a Hungría a través de un país calificado de "país de tránsito seguro» en el que no haya estado expuesto a persecución o a un riesgo de daños graves o en el que se garantice un adecuado nivel de protección. Recordando su jurisprudencia reciente, el Tribunal de Justicia declaró que tal motivo es contrario al art. 33 de la directiva "Procedimientos», para después precisar las consecuencias que de ello se derivan para el procedimiento de asilo, en la 
medida en que la desestimación de las solicitudes de asilo de los interesados, basada en este motivo ilegal, ya ha sido confirmada mediante resolución judicial firme. Según el Tribunal de Justicia, en tal caso, de la directiva «Procedimientos», en particular en relación con el art. 18 de la Carta, que garantiza el derecho de asilo, se desprende que la autoridad que ha desestimado las solicitudes de asilo no está obligada a volver a examinarlas de oficio. No obstante, los interesados sí pueden presentar una nueva solicitud, que será calificada de «solicitud posterior», en el sentido de la directiva «Procedimientos». A este respecto, si bien el art. 33 de esta directiva prevé que una solicitud posterior en la que no se consigne ninguna circunstancia o dato nuevos puede ser considerada inadmisible, la existencia de una sentencia del Tribunal de Justicia en la que se constata que un motivo de inadmisibilidad recogido en una normativa nacional es contrario al derecho de la Unión debe considerarse una circunstancia nueva. Además, con carácter más general, el Tribunal de Justicia declaró que el motivo de inadmisibilidad previsto en el art. 33 de esta directiva no es aplicable cuando la autoridad competente en materia de asilo constate que la desestimación definitiva de la primera solicitud de asilo se produjo contraviniendo el derecho de la Unión. Esta constatación vincula necesariamente cuando la contrariedad con el derecho de la Unión se desprende, como en el caso de autos, de una sentencia del Tribunal de Justicia o cuando haya sido declarada con carácter incidental por un órgano jurisdiccional nacional.

Las autoridades judiciales ante las que se insta el internamiento de un nacional de un tercer país que se halla en situación irregular pueden recibir una solicitud de protección internacional y deben informar al interesado de las condiciones de presentación de dicha solicitud y la persona que haya manifestado su voluntad de solicitar protección internacional ante las autoridades competentes para recibir la solicitud no puede ser internada por no haber suficientes plazas disponibles en los centros de acogida humanitaria [Sentencia de 25 de junio de 2020, Ministerio Fiscal (Autoridad que es probable que reciba una solicitud de protección internacional), C-36/20 PPU, EU:C:2020:495].

En esta sentencia el Tribunal de Justicia ha declarado que el juez de instrucción ante el que se insta el internamiento de un nacional de un tercer país que se halla en situación irregular está incluido entre las «otras autoridades» a las que se refiere el art. 6, apdo. 1, segundo párrafo, de la Directiva 2013/32/UE del Parlamento Europeo y del Consejo, sobre procedimientos comunes para la concesión o la retirada de la protección internacional («directiva sobre procedimientos»), que, pese a ser probable que reciban solicitudes de protección internacional, no son competentes para registrarlas conforme a su derecho nacional. En su 
calidad de «otra autoridad», el juez de instrucción debe informar al solicitante de protección internacional de las condiciones de presentación de la solicitud. El Tribunal de Justicia ha declarado, asimismo, que la imposibilidad de encontrar plaza en un centro de acogida humanitaria no puede justificar el internamiento de un solicitante de protección internacional.

El 12 de diciembre de 2019, una patera a bordo de la que se encontraban cuarenta y cinco nacionales de terceros países, entre ellos VL, nacional malí, fue interceptada por Salvamento Marítimo cerca de la isla de Gran Canaria, lugar donde los desembarcó. Al día siguiente, una autoridad administrativa ordenó la devolución de estas personas e instó su ingreso en un centro de internamiento ante el Juzgado de Instrucción. Tras ser informado de sus derechos por el juez de instrucción, VL le manifestó su intención de solicitar protección internacional. Al no haber suficientes plazas disponibles en los centros de acogida humanitaria, el juez de instrucción acordó el ingreso de VL en un centro de internamiento de extranjeros, en el cual debía tramitarse su solicitud de protección internacional. VL interpuso entonces recurso contra el auto mediante el que se había acordado su internamiento, por considerarlo incompatible con la directiva sobre procedimientos y con la Directiva 2013/33/UE del Parlamento Europeo y del Consejo, por la que se aprueban normas para la acogida de los solicitantes de protección internacional («directiva sobre acogida»). En el marco de este recurso, el juez de instrucción presentó una petición de decisión prejudicial ante el Tribunal de Justicia con el fin de que se dilucide, fundamentalmente, si él mismo como juez de instrucción se encuentra comprendido en el concepto de "otras autoridades», en el sentido del art. 6, apartado 1, párrafo segundo, de la directiva sobre procedimientos y, por tanto, si tiene la consideración de autoridad que es probable que reciba solicitudes de protección internacional. También preguntó al Tribunal de Justicia sobre la legalidad del internamiento.

En primer lugar, el Tribunal de Justicia ha precisado que la interpretación literal del concepto de "otras autoridades que [es] probable que reciban [solicitudes de protección internacional]», en el sentido del art. 6, apdo. 1, párr. segundo, de la directiva sobre procedimientos, y, en particular, la elección del adjetivo «otras» atestigua la voluntad del legislador de la Unión de optar por una definición abierta del círculo de autoridades que, pese a carecer de competencia para registrar las solicitudes de protección internacional, pueden no obstante recibirlas. Por lo tanto, esta expresión puede englobar tanto autoridades administrativas como autoridades judiciales. Esta apreciación queda corroborada por una interpretación contextual de la disposición mencionada. Uno de los objetivos que persigue la directiva sobre procedimientos consiste, de hecho, en garantizar un acceso efectivo, esto es, un acceso tan sencillo como sea posible, al procedimiento de concesión de la protección interna- 
cional. Prohibir que una autoridad judicial reciba solicitudes de protección internacional obstaculizaría la consecución de este objetivo, especialmente en procedimientos muy rápidos, en los que la comparecencia del solicitante de protección internacional ante el juez puede ser la primera ocasión para ejercer el derecho a formular esa solicitud. Por consiguiente, el Tribunal de Justicia ha llegado a la conclusión de que el juez de instrucción ante el que se insta el internamiento de un nacional de un tercer país que se halla en situación irregular a los efectos de su devolución está incluido entre las "otras autoridades» que es probable que reciban solicitudes de protección internacional.

En segundo lugar, el Tribunal de Justicia ha analizado las obligaciones que se imponen al juez de instrucción en su calidad de "otra autoridad». Ha señalado que del art. 6 , apdo. 1 , párrafos segundo y tercero, de la directiva sobre procedimientos se desprende, por un lado, que el juez de instrucción está obligado a facilitar a los solicitantes de protección internacional información sobre las condiciones concretas de presentación de la solicitud de protección internacional. Por consiguiente, el juez de instrucción cumple con lo dispuesto en dicha directiva cuando toma la iniciativa de informar al nacional de un país tercero del derecho a solicitar protección internacional que le asiste. Por otro lado, cuando un nacional de un tercer país le haya manifestado su voluntad de formular dicha solicitud, el juez de instrucción debe dar traslado del expediente a la autoridad competente para el registro de la solicitud con el fin de que el nacional de un tercer país pueda disfrutar de las condiciones materiales de acogida y de la atención sanitaria que se contemplan en el art. 17 de la directiva sobre acogida.

En tercer lugar, el Tribunal de Justicia ha examinado la compatibilidad del internamiento de VL con la directiva sobre procedimientos y la directiva sobre acogida. En primer lugar, ha señalado que debe adoptarse una concepción amplia del concepto de «solicitante de protección internacional», de modo que un nacional de un tercer país adquiere esa condición en el momento en que formula la solicitud de protección internacional. El Tribunal de Justicia ha precisado que el acto de «formular» una solicitud de protección internacional no requiere formalidad administrativa alguna. Por lo tanto, la manifestación por parte de un nacional de un tercer país de su voluntad de solicitar protección internacional ante «otra autoridad», como el juez de instrucción, basta para que se le confiera la condición de solicitante de protección internacional.

En consecuencia, el Tribunal de Justicia ha declarado que, a partir de la fecha en la que VL formuló la solicitud de protección internacional, las condiciones de su internamiento pasaron a regirse por el art. 26, apdo. 1, de la directiva sobre procedimientos y por el art. 8, apdo. 1, de la directiva 
sobre acogida. De una lectura conjunta de estas disposiciones resulta que los Estados miembros no pueden internar a una persona por la única razón de que sea solicitante de protección internacional, y que los motivos y las condiciones de internamiento, así como las garantías de los solicitantes internados, deben ser conformes con la directiva sobre acogida. Habida cuenta de que el art. 8, apdo. 3, párr. primero, de esta última directiva enumera con carácter exhaustivo los distintos motivos que pueden justificar un internamiento, y de que la imposibilidad de encontrar plaza en un centro de acogida humanitaria para un solicitante de protección internacional no corresponde a ninguno de los seis motivos de internamiento mencionados en dicha disposición, el internamiento de VL es contrario a lo dispuesto en la directiva sobre acogida.

Los Estados miembros deben conceder una indemnización a todas las víctimas de los delitos dolosos violentos, incluidas las que residen en su propio territorio, y dicha indemnización no debe cubrir la reparación íntegra de los daños, pero su importe no puede ser puramente simbólico (Sentencia de 16 de julio de 2020, Presidenza del Consiglio dei Ministri, C-129/19, EU:C:2020:566).

En esta sentencia, el Tribunal de Justicia, reunido en Gran Sala, declaró, en primer lugar, que el régimen de la responsabilidad extracontractual de un Estado miembro por el daño causado por la infracción de ese derecho ha de aplicarse, al no haber transpuesto ese Estado miembro en su debido momento la Directiva 2004/80/CE del Consejo, sobre indemnización a las víctimas de delitos, a las víctimas residentes en el referido Estado miembro, en cuyo territorio se ha cometido el delito doloso violento. En segundo lugar, el Tribunal de Justicia declaró que una indemnización a tanto alzado, concedida a las víctimas de una agresión sexual en virtud de un régimen nacional de indemnización a las víctimas de delitos dolosos violentos, no puede calificarse de «justa y adecuada» en el sentido de esa misma disposición si se fija sin tener en cuenta la gravedad de las consecuencias que para las víctimas tiene el delito cometido y, por lo tanto, no supone una contribución adecuada a la reparación del perjuicio material y moral sufrido.

En el caso de autos, BV, ciudadana italiana residente en Italia, fue víctima de una agresión sexual cometida en el territorio de ese Estado miembro. Sin embargo, a causa de la fuga de los autores de esta agresión, no se pudieron abonar a la víctima los 50000 euros a los que, en concepto de daños y perjuicios, aquellos habían sido condenados. En febrero de 2009, BV demandó a la Presidenza del Consiglio dei Ministri (Presidencia del Consejo de Ministros, Italia), reclamando la reparación del daño que afirmaba haber sufrido como consecuencia de que la República Italiana no hubiera transpuesto en su debido 
momento la Directiva 2004/80. A tenor del art. 12, apdo. 2, de la directiva, «todos los Estados miembros garantizarán que sus normas nacionales establecen la existencia de un régimen de indemnización para las víctimas de delitos dolosos violentos cometidos en sus respectivos territorios, que asegure a las víctimas una indemnización justa y adecuada». A lo largo de dicho procedimiento, la Presidencia del Consejo de Ministros fue condenada, en primera instancia, a pagar a BV la suma de 90000 euros, cantidad que en apelación se redujo a 50000 euros.

El tribunal remitente, ante el que la Presidencia del Consejo de Ministros interpuso un recurso de casación, se preguntaba, por un lado, sobre la posibilidad de aplicar el régimen de la responsabilidad extracontractual de un Estado miembro - como consecuencia de una tardía transposición por su parte de la Directiva 2004/80 - a las víctimas de los delitos dolosos violentos que no se encuentran en situación transfronteriza. Por otra lado, el tribunal remitente albergaba dudas acerca de si es «justa y adecuada», en el sentido del art. 12, apdo. 2, de la Directiva 2004/80, la cantidad a tanto alzado de 4800 euros, prevista por la normativa italiana como indemnización a las víctimas de agresiones sexuales.

Por lo que respecta a la primera de esas cuestiones prejudiciales, el Tribunal de Justicia recordó, en primer lugar, los requisitos que permiten determinar la responsabilidad de los Estados miembros por los daños causados a los particulares como consecuencia de violaciones del derecho de la Unión, a saber, la existencia de una norma de derecho de la Unión infringida que confiera derechos a los particulares, una infracción suficientemente caracterizada de esa norma y un nexo causal entre esa infracción y los daños sufridos por los particulares. En el caso de autos, teniendo en cuenta el tenor literal del art. 12, apdo. 2, de la Directiva 2004/80, su contexto y sus objetivos, el Tribunal de Justicia destacó, en particular, que, mediante esa disposición, el legislador de la Unión no había optado por el establecimiento, por parte de cada Estado miembro, de un régimen de indemnización específico, limitado únicamente a las víctimas de delitos dolosos violentos que se encuentren en situación transfronteriza, sino por la aplicación, en favor de dichas víctimas, de los regímenes nacionales de indemnización a las víctimas de delitos dolosos violentos cometidos en los respectivos territorios de los Estados miembros. Al final de su análisis, el Tribunal de Justicia consideró que la Directiva 2004/80 obliga a todos los Estados miembros a dotarse de un régimen de indemnización que cubra a todas las víctimas de delitos dolosos violentos cometidos en sus territorios y no solo a las víctimas que se encuentren en situación transfronteriza. El Tribunal de Justicia dedujo de lo anterior que la Directiva 2004/80 confiere el derecho a obtener una indemnización justa y adecuada no solo a las víctimas de delitos dolosos violentos cometidos en el territorio 
de un Estado miembro que se encuentren en situación transfronteriza, sino también a las víctimas que residan habitualmente en el territorio del Estado miembro en el que se ha cometido el delito. Por consiguiente, siempre que se cumplan los otros dos requisitos antes mencionados, un particular tiene derecho a indemnización por los daños que le ha causado el incumplimiento, por parte de un Estado miembro, de su obligación derivada del art. 12, apdo. 2 , de la Directiva 2004/80, con independencia de si el particular se encontraba o no en tal situación transfronteriza en el momento en que fue víctima del delito en cuestión.

Por lo que respecta a la segunda cuestión prejudicial, el Tribunal de Justicia consideró que, al no existir en la Directiva 2004/80 indicación alguna sobre el importe de la indemnización que se considera que corresponde a una indemnización «justa y adecuada», la referida disposición reconoce a los Estados miembros un margen de apreciación a tales efectos. Sin embargo, aunque esta indemnización no debe garantizar necesariamente una reparación completa del daño material y moral sufrido por la víctima del delito doloso violento, tampoco puede tener un carácter meramente simbólico o manifiestamente insuficiente en relación con la gravedad de las consecuencias que para las víctimas tiene el delito cometido. Según el Tribunal de Justicia, la indemnización concedida a esas víctimas en virtud de esta disposición debe efectivamente compensar, en una medida adecuada, el padecimiento que estas sufrieron. A este respecto, el Tribunal de Justicia también aclaró que la indemnización a tanto alzado para esas víctimas puede calificarse de «justa y apropiada", siempre que el baremo de indemnizaciones sea suficientemente detallado, de modo que se evite que la indemnización a tanto alzado prevista para un determinado tipo de delito pueda resultar, teniendo en cuenta las circunstancias de cada caso concreto, manifiestamente insuficiente.

Una acción ejercitada por las autoridades de un Estado miembro contra comerciantes establecidos en otro Estado miembro mediante la que dichas autoridades solicitan, con carácter principal, que se declare la existencia de infracciones consistentes en prácticas comerciales desleales presuntamente ilícitas y que se ordene su cesación está comprendida en el concepto de «materia civil y mercantil» a efectos del reglamento relativo a la competencia judicial, el reconocimiento y la ejecución de resoluciones judiciales en materia civil y mercantil (Sentencia de 16 de julio de 2020, Movic y otros, C-73/19, EU:C:2020:568).

Mediante su cuestión prejudicial, el tribunal remitente preguntaba, en lo esencial, si está comprendida en el art. 1, apdo. 1, del Reglamento (UE) 1215/2012 del Parlamento Europeo y del Consejo, relativo a la compe- 
tencia judicial, el reconocimiento y la ejecución de resoluciones judiciales en materia civil y mercantil, una acción ejercitada por las autoridades de un Estado miembro contra profesionales establecidos en otro Estado miembro, mediante la cual dichas autoridades solicitan, con carácter principal, que se declare la existencia de infracciones consistentes en prácticas comerciales desleales supuestamente ilegales y se ordene su cesación, además de, con carácter accesorio, que se ordenen medidas de publicidad, que se impongan multas coercitivas por las infracciones comprobadas y que se declare que las futuras infracciones podrán acreditarse mediante simple acta redactada por un funcionario adscrito a una de esas autoridades que haya prestado juramento.

Para garantizar, en la medida de lo posible, la igualdad y la uniformidad de los derechos y obligaciones que resultan del Reglamento 1215/2012 para los Estados miembros y los interesados, no cabe interpretar el concepto de «materia civil y mercantil» que figura en el art. 1, apdo. 1, de ese reglamento como una mera remisión al derecho interno de un Estado miembro. Hay que considerar que se trata de un concepto autónomo, que debe ser interpretado refiriéndose, por una parte, a los objetivos y al sistema de dicho reglamento $y$, por otra, a los principios generales que se deducen de todos los ordenamientos jurídicos nacionales. Asimismo, como se desprende, en particular, del considerando 10 del Reglamento 1215/2012, la necesidad de garantizar el buen funcionamiento del mercado interior y la de evitar, para el funcionamiento armonioso de la justicia, que se dicten resoluciones contradictorias en los Estados miembros exigen una interpretación amplia del citado concepto de «materia civil y mercantil».

El Tribunal de Justicia recuerda también que ya había declarado de forma reiterada que, si bien determinados litigios surgidos entre una autoridad pública y una persona de derecho privado pueden estar comprendidos en el ámbito de aplicación del Reglamento 1215/2012, la situación es distinta cuando la autoridad pública actúa en ejercicio del poder público. En efecto, la manifestación de prerrogativas de poder público por una de las partes en el litigio, en virtud de su ejercicio de poderes exorbitantes en relación con las normas de derecho común aplicables a las relaciones entre particulares, excluye tal litigio del concepto de «materia civil y mercantil» a efectos del art. 1, apdo. 1, del Reglamento 1215/2012. Respecto a las acciones de cesación y al concepto de "materia civil y mercantil», a efectos del art. 1, apdo. 1, del Reglamento 1215/2012, el Tribunal de Justicia ya ha declarado que la acción de prohibición del uso por los comerciantes de cláusulas abusivas, en el sentido de la Directiva 93/13, en los contratos que celebran con los consumidores, en la medida en que tiene por objeto someter determinadas relaciones de derecho privado al control jurisdiccional, está comprendida dentro del 
concepto de «materia civil». Esta jurisprudencia fue posteriormente reiterada y extendida con carácter más general a las acciones de cesación a que se refiere la Directiva 2009/22.

No obstante, en lo que respecta a la forma de ejercitar la acción, señala que las acciones de que se trata en el litigio principal no fueron entabladas por personas de derecho privado, como consumidores u organismos de protección del consumidor, sino por las autoridades belgas encargadas por el Estado miembro interesado de garantizar, en particular, la protección de los consumidores. De la legislación nacional se desprende que la posición procesal de las autoridades belgas es, a este respecto, comparable a la de una organización de protección de los consumidores. Además, la normativa nacional de que se trata en el litigio principal tampoco parece reservar a las autoridades belgas que menciona normas de reconocimiento del interés en ejercitar la acción que les confieran condiciones exorbitantes para su ejercicio en comparación con las establecidas para los demás demandantes. Apunta que la defensa del interés general no puede confundirse con el ejercicio de las prerrogativas del poder público.

En los litigios principales, los requisitos establecidos para que las autoridades belgas tengan interés en ejercitar la acción no parecen implicar el ejercicio de prerrogativas de poder público, sin perjuicio de las comprobaciones que deberá efectuar el tribunal remitente. Por consiguiente, una acción ejercitada por las autoridades de un Estado miembro contra comerciantes establecidos en otro Estado miembro mediante la que dichas autoridades solicitan, con carácter principal, que se declare la existencia de infracciones consistentes en prácticas comerciales desleales presuntamente ilícitas y que se ordene su cesación está comprendida en el concepto de «materia civil y mercantil» a efectos del art. 1, apdo. 1, del Reglamento 1215/2012.

Las víctimas del naufragio de un buque que enarbola pabellón panameño pueden entablar ante los tribunales italianos una acción de responsabilidad contra las organizaciones italianas que clasificaron y certificaron dicho buque, $y$ estas organizaciones únicamente podrían ampararse en la inmunidad de jurisdicción en la medida en que sus actividades hubieran sido expresión del poder público del Estado panameño (Sentencia de 7 de mayo de 2020, Rina, C-641/18, EU:C:2020:349).

En esta sentencia el Tribunal de Justicia ha declarado, en primer lugar que una demanda de indemnización interpuesta contra personas jurídicas de derecho privado que ejercen una actividad de clasificación y de certificación de buques por cuenta y por delegación de un Estado tercero está comprendida en el concepto de «materia civil y mercantil», a efectos del art. 1, apdo. 1, del Reglamento (CE) 44/2001 del Consejo, relativo a la competencia judicial, 
el reconocimiento y la ejecución de resoluciones judiciales en materia civil y mercantil («Reglamento Bruselas I») y, por tanto, queda incluida en el ámbito de aplicación de ese reglamento, en tanto la referida actividad no se ejerza en virtud de prerrogativas de poder público en el sentido del derecho de la Unión.

En segundo lugar, ha declarado que el principio de derecho internacional consuetudinario sobre la inmunidad de jurisdicción no se opone al ejercicio, por parte del órgano jurisdiccional nacional que conoce del asunto, de la competencia jurisdiccional que prevé dicho reglamento en un litigio relativo a una demanda de esta naturaleza cuando ese órgano jurisdiccional compruebe que las citadas organizaciones no han recurrido a las prerrogativas de poder público en el sentido del derecho internacional.

En 2006, el buque Al Salam Boccaccio '98, que enarbolaba pabellón de Panamá, naufragó en el mar Rojo, cobrándose más de mil víctimas. Los familiares de las víctimas y de los pasajeros que sobrevivieron al naufragio interpusieron ante el Tribunale di Genova (Tribunal de Génova, Italia) una demanda contra Rina SpA y el Ente Registro Italiano Navale (conjuntamente, «sociedades Rina»), sociedades que llevaron a cabo las operaciones de clasificación y de certificación del buque naufragado y cuyo domicilio social se encuentra en Génova. Los demandantes solicitaban la indemnización de los perjuicios materiales y morales derivada de la eventual responsabilidad civil de las sociedades Rina, alegando que las citadas operaciones de clasificación y de certificación se encontraban en el origen del naufragio. Las sociedades Rina alegaron la falta de competencia del tribunal ante el que se interpuso la demanda invocando el principio de inmunidad de jurisdicción, dado que las operaciones de clasificación y de certificación que llevaron a cabo se hicieron por delegación de Panamá y, consecuentemente, son manifestación de las prerrogativas soberanas del Estado delegante. Preguntándose si los órganos jurisdiccionales italianos eran competentes, el tribunal ante el que se interpuso la demanda planteó una cuestión prejudicial.

En primer lugar, el Tribunal de Justicia ha abordado la interpretación del concepto de «materia civil y mercantil», a efectos del art. 1, apartado 1, del Reglamento Bruselas I, teniendo en cuenta las actividades de clasificación y de certificación de buques llevadas a cabo por las sociedades Rina, por delegación y por cuenta de Panamá, y a fin de dilucidar si los órganos jurisdiccionales italianos son competentes en virtud del art. 2, apdo. 1, de dicho reglamento. 2 Para empezar, el Tribunal de Justicia ha recordado que, si bien determinados litigios surgidos entre una autoridad pública y una persona de derecho privado pueden estar comprendidos en el ámbito de aplicación del Reglamento Bruselas I cuando la acción judicial tenga por objeto actos realizados sin implicar el ejercicio del poder público (iure gestionis), la situación es 
distinta cuando la autoridad pública actúa en ejercicio del poder público (iure imperii). A este respecto, el Tribunal de Justicia ha destacado que carece de relevancia que determinadas actividades se hayan llevado a cabo por delegación de un Estado: en efecto, el mero hecho de que determinadas facultades hayan sido delegadas por un acto de poder público no implica que estas facultades se ejerzan iure imperii. Lo mismo cabe decir del hecho de que las operaciones en cuestión se hayan desempeñado por cuenta y en interés de Panamá, ya que actuar en nombre del Estado no siempre implica el ejercicio de la autoridad pública. Además, el hecho de que determinadas actividades tengan una finalidad pública no constituye, en sí mismo, un elemento suficiente para calificarlas como actividades desempeñadas iure imperii.

De tal modo, el Tribunal de Justicia ha subrayado que, para determinar si las operaciones en cuestión se realizaron en ejercicio del poder público, el criterio pertinente es el recurso a poderes exorbitantes en relación con las normas aplicables en las relaciones entre particulares. A tal efecto, el Tribunal de Justicia ha señalado que las operaciones de clasificación y de certificación llevadas a cabo por las sociedades Rina consistían únicamente en acreditar que el buque cumplía los requisitos establecidos en las disposiciones aplicables y, en caso afirmativo, en expedir los certificados correspondientes. La interpretación y la elección de los requisitos técnicos aplicables estaban reservadas, por su parte, a las autoridades panameñas. Ciertamente, la verificación del buque por una sociedad de clasificación y de certificación puede llevar, en su caso, a la revocación del certificado por falta de conformidad con esos requisitos. No obstante, dicha revocación no deriva de la facultad de decisión de las citadas sociedades, que actúan dentro del marco reglamentario previamente definido. Si un buque ya no puede navegar tras ser revocado un certificado, ello se debe a la sanción que impone la ley. En consecuencia, el Tribunal de Justicia ha concluido que, sin perjuicio de las comprobaciones que debe hacer el tribunal remitente, las operaciones de clasificación y de certificación llevadas a cabo por las sociedades Rina no pueden considerarse realizadas en el ejercicio de prerrogativas de poder público en el sentido del derecho de la Unión.

En segundo lugar, el Tribunal de Justicia ha examinado la eventual incidencia, a efectos de la aplicabilidad del Reglamento Bruselas I, de la excepción fundada en el principio de derecho internacional consuetudinario atinente a la inmunidad de jurisdicción. El Tribunal de Justicia ha destacado que ya ha declarado que, en la situación actual de la práctica internacional, la inmunidad de jurisdicción de los Estados no tiene un valor absoluto, sino que se reconoce generalmente cuando el litigio se refiere a actos de soberanía realizados iure imperii. En cambio, puede excluirse si la acción judicial tiene por objeto actos que no pertenecen al ámbito del poder público. La inmunidad de jurisdicción de las organizaciones de derecho privado, como las sociedades 
Rina, generalmente no se reconoce en relación con las operaciones de clasificación y de certificación de buques si estas no se han llevado a cabo iure imperii en el sentido del derecho internacional. En consecuencia, el Tribunal de Justicia ha concluido que dicho principio no se opone a la aplicación del Reglamento Bruselas I en un litigio como el del asunto principal, cuando el órgano jurisdiccional que conoce del asunto compruebe que las organizaciones de clasificación y de certificación en cuestión no han recurrido a las prerrogativas de poder público en el sentido del derecho internacional. 